\title{
TOWARD THE EMERGENCE OF ENTREPRENEURIAL OPPORTUNITIES: ORGANIZING EARLY-PHASE NEW- VENTURE CREATION SUPPORT SYSTEMS
}

\begin{tabular}{|c|l|}
\hline Journal: & Academy of Management Review \\
\hline Manuscript ID & AMR-2019-0040-Original.R4 \\
\hline Manuscript Type: & Original Manuscript \\
\hline Theoretical Perspectives: & $\begin{array}{l}\text { Complexity and Systems theory, Industrial organization/economics, } \\
\text { Social capital theory }\end{array}$ \\
\hline Topic Areas: & $\begin{array}{l}\text { Entrepreneurial Ecosystems < Entrepreneurship, Entrepreneurial } \\
\text { opportunities (General) < Entrepreneurship Opportunities < } \\
\text { Entrepreneurship, Incubators < New venture strategies < } \\
\text { Entrepreneurship }\end{array}$ \\
\hline Abstract: & $\begin{array}{l}\text { Support systems for early venturing efforts need to be harmonious with } \\
\text { the emergent nature of those efforts. With current literature treating the } \\
\text { conceptions of new ventures as exogenous, there has been limited focus } \\
\text { on the transition of venturing efforts from nebulous, open-ended, and } \\
\text { accidental toward becoming scalable, focused, and deliberate. We } \\
\text { develop a dynamic model for organizing support systems for the early } \\
\text { phases of new-venture creation, where scattered ideas evolve into } \\
\text { venture concepts as tokens, frames, and premises for further action. By } \\
\text { viewing venturing efforts and opportunities as emergent and drawing on } \\
\text { the literature on complexity and organizational space, we propose } \\
\text { openness, self-selection, visibility, and connectivity as the defining } \\
\text { characteristics for organizing support systems. In contrast to literature's } \\
\text { predominant focus on a predictive, linear approach, we expand the } \\
\text { theoretical scope of support systems to include organizing that is more } \\
\text { attuned to the uncertain and nonlinear nature of new venture creation } \\
\text { that they support. Our work has broader implications for organizing } \\
\text { uncertain early-phase development processes. }\end{array}$ \\
\hline
\end{tabular}




\title{
Toward the Emergence of Entrepreneurial Opportunities:
}

\section{Organizing Early-phase New-venture Creation Support Systems}

\author{
Sujith Nair ${ }^{1}$ \\ Umeå University, Sweden \\ sujith.nair@umu.se \\ Medhanie Gaim ${ }^{2}$ \\ Umeå University, Sweden \\ medhanie.gaim@umu.se \\ Dimo Dimov \\ University of Bath, UK \\ Reykjavik University, Iceland \\ d.p.dimov@bath.ac.uk
}

We would like to thank Associate Editor Sharon Alvarez, Editor Jay Barney and the three anonymous reviewers for their insightful and developmental comments. We also thank Tor Hernes, Thorbjørn Knudsen, Joep Cornelissen, Devi R. Gnyawali, Wendy Smith, Jim Andersén, Jessica Eriksson and Lucas Haskell for their valuable feedback on prior drafts. Earlier version of this paper was presented at the 2018 annual Academy of Management meeting in Chicago, IL.

Sujith and Medhanie would like to acknowledge the funding from Riksbankens Jubileumsfond (P19-0597:1) for partly supporting this research.

A video abstract of this paper can be found at https:/www.youtube.com/watch? $\mathrm{v}=\mathrm{nDUZgGapMnM \& \text {feature=youtu.be }}$

\footnotetext{
${ }^{1}$ The corresponding author is Sujith Nair, Umeå School of Business, Economics and Statistics, Umeå University, Biblioteksgränd 6, 90187, Umeå, Sweden, email: Sujith.nair@umu.se

1,2 The first and second authors contributed equally in developing the paper.
} 


\title{
Toward the Emergence of Entrepreneurial Opportunities: Organizing Early-phase New-venture Creation Support Systems
}

\begin{abstract}
Support systems for early venturing efforts need to be harmonious with the emergent nature of those efforts. With current literature treating the conceptions of new ventures as exogenous, there has been limited focus on the transition of venturing efforts from nebulous, open-ended, and accidental toward becoming scalable, focused, and deliberate. We develop a dynamic model for organizing support systems for the early phases of new-venture creation, where scattered ideas evolve into venture concepts as tokens, frames, and premises for further action. By viewing venturing efforts and opportunities as emergent and drawing on the literature on complexity and organizational space, we propose openness, self-selection, visibility, and connectivity as the defining characteristics for organizing support systems. In contrast to literature's predominant focus on a predictive, linear approach, we expand the theoretical scope of support systems to include organizing that is more attuned to the uncertain and nonlinear nature of new venture creation that they support. Our work has broader implications for organizing uncertain early-phase development processes.
\end{abstract}

Keywords: entrepreneurship; entrepreneurial opportunities; entrepreneurial ecosystems; emergence; new-venture creation. 
"Every great entrepreneur can point to several coffee chats that opened doors, sparked ideas, and formed important new relationships. The StartUp HERE Toronto Café is focused on helping to easily build relationships between entrepreneurs and drive Toronto's startup community. It is a place to connect with peers, funders, and investors, subject matter experts, and just generally great people who have an interest in growing Toronto's startup community." (StartUp HERE Toronto Café, 2018).

If we play the story of a new venture backward, we would see its gradual shrinking, the disappearance of its organizing elements or structures, dissolution into ideas and discourse among founding team members and early supporters, and - beyond the point at which various places, events, or situations bring those members together - scattering into disparate individual experiences and life stories. In this rewinding process, the precise structure and purpose of the venture dissolve into its disjointed pre-existence, in which no reliable tokens of its future existence can be found. Indeed, the further back we go, the more obscure the eventual pathway becomes. The progressive unfolding and forward revelation of the venturing process poses the question of how it can be supported and facilitated. This represents a significant organizing challenge given the uncertainty under which new ventures and opportunities emerge inextricably from amorphous yet purposeful interactions between entrepreneurs and their scattered ideas (Alvarez \& Barney, 2005; Dimov, 2011). Therefore, in line with the principle of requisite variety (Ashby, 1956), any support system for early venturing efforts requires consonance with the uncertain and nonlinear nature of those efforts. Not every effort will succeed, but entrepreneurial success can come from anywhere.

Support systems are organizations, such as incubators, accelerators, maker spaces, and startup cafes, within an entrepreneurial ecosystem that facilitate new-venture creation by providing essential resources (Amezcua, Grimes, Bradley, \& Wiklund, 2013; Autio, Nambisan, Thomas, \& Wright, 2018; Feldman, Siegel, \& Wright, 2019). When considering 
support for new venture creation; we can distinguish two qualitatively different, yet conflated, phases to the process. An early phase culminates with an articulation of the elements of a concept for a venture - that emerges from the scattered ideas, behaviors, and intentions of prospective entrepreneurs - as a holistic token, frame, and premise for further action (Dimov, 2020; Vogel, 2016). The venture concept's role as a token enables the entrepreneurs to refer to what they are doing; as a frame, it serves to organize their further actions and define aspirational milestones; and its nature as a premise suggests that it is tentative and likely to evolve with new developments. A subsequent late phase involves developing elements of the venture concept toward achieving what the entrepreneurial community calls "product-market fit" as a gateway to ultimate opportunity realization (McDonald \& Gao, 2019; Shankar \& Shepherd, 2019).

Ignoring the vital distinction between early and late phases and the resulting conflation will result in a mismatch where the nature of "organizing" the support system will not reflect the "organized" and the "organization" of what it supports. The focus in research (see, for example, Clayton, Feldman, \& Lowe, 2018; Cohen, Bingham, \& Hallen, 2019; Pauwels, Clarysse, Wright, \& Van Hove, 2016) has been on organizing in terms of supporting new ventures along their more deliberate trajectories, overlooking the early phases, such as those taking place at the StartUp HERE Toronto Café. Accordingly, the venture conceptions are treated as exogenous, as given, and ready to be picked up by late-phase support systems such as incubators, raising essential questions about the formation and quality of their selection pool. Without a clear and in-depth discussion of how the two phases differ, and corresponding knowledge on how to organize support systems, scholars might treat them as congruent phenomena and overlook the distinctive processes underlying each. In this regard, we direct attention to the underlying processes that help us understand the behavior and organizing features of the early-phase support systems, and pose the following research question: How 
can support systems be organized to enable the actions and interactions of prospective entrepreneurs toward the emergence of venture concepts?

The focus on early-phase support systems, defined as organizations facilitating the emergence of venture concepts as gateways to entrepreneurial efforts, invites attention to a wide range of empirical phenomena such as startup cafes, startup weekends, startup campuses, innovation boot camps, and hackathons, which remain undertheorized. The early phase development processes in these settings are vital to new venture creation because they give rise to requisite variety, integration across ideas, and success in uncertain environments (Adner \& Levinthal, 2008; Alvarez, Barney, \& Anderson, 2013; Brown \& Eisenhardt, 1997; Dougherty \& Dunne, 2012). The early phase of new venturing is uncertain (Alvarez \& Barney, 2005; Townsend, Hunt, McMullen, \& Sarasvathy, 2018) and non-linear, where changing one part of the configuration generates unpredictable outcomes (Mcmullen \& Dimov, 2013; Selden \& Fletcher, 2015). As such, our conception of the early-phase support system reflects the nature of new venturing that it supports. This conception differs from that of the existing literature, whose predominant focus has been on organizing around predictive selection and matching (Aaboen, 2009; Aerts, Matthyssens, \& Vandenbempt, 2007), where new ventures progress towards set goals following sequential and often standardized processes (Bergek \& Norrman, 2008; Clayton et al., 2018; Cohen et al., 2019).

We conceptualize how non-linear and non-predictive (Packard \& Clark, 2019) ways of organizing early-phase support systems enable the actions and interactions of prospective entrepreneurs toward the emergence of venture concepts as gateways for further, more deliberate action. Our framework generates insights for organizational interventions that facilitate the simultaneous self-selection of entrepreneurs (Lazar et al., 2020) and the nonpredictive emergence of opportunities in the new-venture creation process. It demonstrates how the interplay between the organizing characteristics of openness, self-selection, visibility, and 
connectivity creates the potential for venture concepts to emerge. Further, our theorizing has broader implications for organizing in settings where uncertain early-phase development processes are prominent.

\section{ENTREPRENEURIAL OPPORTUNITIES}

Given a focal new venture as a productive entrepreneurial effort, the sense of entrepreneurial opportunity arises from the desire to understand and explain the venture's emergence where some while ago it did not exist. First, from the perspective of creating a new venture, various elements need to come together: i.e., a product or service and the processes, materials, and actors involved in its production and market exchange. Thus, the opportunity can be described in terms of a specific business model or arrangement of artifacts that make the business viable (Berglund, Bousfiha, \& Mansoori, 2020; Dimov, 2016; Selden \& Fletcher, 2015). Second, from the perspective of the venture's competitive viability, the opportunity can be described as a competitive imperfection that cannot necessarily be identified beforehand but arises concurrently with the endogenous actions of entrepreneurial actors (Alvarez \& Barney, 2005, 2007). Third, from a time perspective, the opportunity is expressed in the entrepreneurial intent of an acting individual or team on an open-ended, nonlinear journey in which such evolving intent may be the only constant (McMullen \& Dimov, 2013). In combination, these points suggest that an opportunity emerges endogenously through path-dependent and causally ambiguous processes (Alvarez et al., 2013).

Viewing such gradual emergence alongside the acting entrepreneur - without whose action the journey would not unfold - it becomes clear that the opportunity's articulation evolves from a tentative idea prone to attracting skepticism to a focused pitch eliciting confidence and commitment. While initial ideas are scattered and incomplete representations of the possible future venture, and thus vague in regard to their value-creation potential, a venture concept represents an intermediary articulation of that potential, inviting evaluation and refinement. In 
this regard, the venture concept - as the earliest articulation of the value-creation elements represents a milestone in opportunity emergence (Vogel, 2016). At this early point, it serves as a reference to what the entrepreneur is doing, that can be articulated.

To the extent that we cannot know THE opportunity that will ultimately emerge from the entrepreneur's efforts, we refer to it as a venture concept. It acts as a watershed between an early phase of the venturing process, in which opportunities are but scattered, initial, and tentative ideas that coalesce in venture concepts, and a late phase, with deliberate efforts to refine, evaluate, and develop a specific venture concept. Thus, the venture concept creates a focal meaning for other actors (Garud \& Giuliani, 2013), provides a frame for further action, and can be leveraged to acquire commitments or resources from them (Dimov, 2020). The early phase of opportunity emergence thus captures how scattered ideas are combined, recombined, and transformed into a more ordered and articulate venture concept. By emergence, we mean "the process by which patterns or global-level structures arise with interactive, local-level processes. This 'structure' or 'pattern' cannot be understood or predicted from the behavior or properties of the component units alone [...] In the doctrine of emergence, the combination of elements with one another brings with it something that was not there before." (Mihata, 1997: 31).

As emerging artifacts, opportunities can only be understood by considering how individuals and their knowledge are transformed (Lichtenstein et al., 2006). This transformation, which occurs through serendipitous and purposeful intersubjective interactions between heterogeneous actors, is uncertain and complex (Alvarez \& Barney, 2005; Augier \& Sarasvathy, 2004; Roundy, Brockman, \& Bradshaw, 2017; Selden \& Fletcher, 2015). We illustrate the notion of opportunity emergence through a stylistic and hypothetical example. Our reconstruction retrospectively traces events leading to realized opportunities from venture 
concepts and venture concepts from initial scattered ideas, although we present the emergence prospectively for ease of analytical presentation as depicted in Figures 1 and 2.

Insert Figures 1 and 2 about here

Consider a chef (A) who has recently arrived in a city with dreams of becoming a food entrepreneur. At the city's university, a food scientist (B) has recently developed a new preservation technology as part of her study. She is considering how to make her technology useful. At the same university, a plant scientist (C) is independently working on forest microenvironment technologies. In a nearby institute, a forester (D) has been working for many years on new tree-planting patterns to improve their survival. All four individuals attend an initiative for startup creation hosted at the university.

At time t0, the assumption is that all four (A1, B1, C1, and D1) have initial ideas and intentions (represented by "1") before they interact. Some of them intentionally explore the possibilities their ideas present, while others do so by chance. At t1, because of their similar professions, interaction ensues between the two scientists but does not produce a shared idea. However, the food scientist receives a new input from this interaction $(\mathrm{B} 1 \rightarrow \mathrm{B} 2)$, while the plant scientist does not (C1-C1). At 2 , the food scientist interacts with the chef, while the plant scientist converses with the forester. At $\mathrm{t} 3$, the chef and the food scientist connect at some level and manage to create a shared idea. As a result of this interaction, their ideas evolve $(\mathrm{A} 1 \rightarrow \mathrm{A} 2$ and $\mathrm{B} 2 \rightarrow \mathrm{B} 3$ ). At this stage, an industrial designer (E) joins the conversation and takes the shared idea of the chef and the food scientist to the next level. Because the plant scientist and the forester do not connect, their interaction ends, but the forester has gained new insights into resolving some of the challenges she has been facing $(\mathrm{D} 1 \rightarrow \mathrm{D} 2)$. At 4 , the interactions between the chef, the food scientist, and the industrial designer lead to shared ideas (A3, B4, E2), 
represented by the intersection of the three circles. This intersection of ideas, wherein they combine, recombine, and transform, gives rise to a venture concept "ABE"; this concept might be a subjective conceptualization in the three individuals' minds, but may also be inscribed as an artifact, such as a concept paper or merely a sketched diagram. The interactions between the chef, the food scientist, and the industrial designer might not have occurred automatically because of their disconnectedness and inherent heterogeneity. However, although random and nonlinear, their interactions were facilitated through interventions (e.g., through spatial dimensions). Early-phase support systems can, therefore, catalyze the emergence of venture concepts.

The new venturing phase, from the venture concept to realized opportunity, is well researched from the perspective of late-phase support systems, such as business incubators and accelerators. As Figure 2 shows, both internal and external interactions advance opportunities from venture concepts to their ultimate realization (Dimov, 2016). Internal interactions, such as interventions by business coaches, can enhance external interactions with potential customers, funders, and suppliers, and lead to acquiring new team members. These interactions might eventually lead to market desirability, operational or technical feasibility, and financial viability, thereby transforming an opportunity from an initial venture concept to something actually instituted in the market.

\section{LINEAR AND PREDICTIVE VIEW OF SUPPORT SYSTEMS}

An entrepreneurial ecosystem consists of multiple and overlapping sets of attributes and institutions, including physical spaces, networks, startup culture, and financing, that encourage entrepreneurial activity within a region (Spigel, 2017; Spigel \& Harrison, 2018). Late-phase support systems, such as incubators and accelerators, are essential components of an ecosystem that facilitates new venture creation, by providing critical tangible and intangible resources (Clayton et al., 2018; Cohen et al., 2019; Spigel, 2017, p. 54). The temporal processes 
underlying incubators and accelerators are premised on new-venture creation as a staged lifecycle (Cardon, Zietsma, Saparito, Matherne, \& Davis, 2005). Such a staged life cycle view of organizing brings with it the notion of a prefigured trajectory from the beginning to the endstage based on institutional rules or programs that progress in a prescribed sequence (van de Ven \& Poole, 1995).

In both design and function, incubators and accelerators support startups in which a team has supposedly formed around a 'scalable idea' (Nair \& Blomquist, 2019). The venture concepts are supposed to be formed already with limited effort made to increase the diversity and quality of the ideas on which they are based. Incubators mostly rely on selection criteria such as a written business plan, the idea's innovativeness, growth prospects, team members' coachability, and the team's technical, managerial, and financial skills (Aaboen, 2009; Aerts et al., 2007). Moreover, incubators rely on market interest and commercial viability (Bruneel, Ratinho, Clarysse, \& Groen, 2012; Nair \& Blomquist, 2020; Rubin, Aas, \& Stead, 2015) as a means of moving the incubatees along the process. Accelerators employ a predesigned curriculum and highly organized schedule for a cohort of competitively selected startups (Pauwels et al., 2016). All these point to a linear and predictive approach where support system managers make decisions regarding feasibility and scalability in a structured sequential process. Viewing new-venture creation as staged life cycle process profoundly influences how incubators and accelerators are organized. Although such organizing is meritorious on its own way, it leaves little room for emergence.

In contrast, instead of support system managers or gatekeepers trying to predict feasibility and team members' ability - the predominant view - we promote a non-predictive approach where opportunities emerge in non-linear interactions. We argue that a non-predictive approach is better suited to the fast-changing and uncertain early phase of new-venture creation (Alvarez \& Barney, 2005; Alvarez et al., 2013; Dew, Read, Sarasvathy, \& Wiltbank, 2008; Packard \& 
Clark, 2019; Sarasvathy, 2001). Such a focus has the potential to increase the quality of venture concepts that reach late-phase support systems: something that is neglected in the predominant organizing of support systems. In this area, we agree with Anderson, Meyer, Eisenhardt, Carley, \& Pettigrew's (1999: 233) notion that “organizational scholars seldom come to grips with nonlinear phenomena; instead, they tend to model phenomena as if they were linear in order to make them tractable." This reductionist approach might constrain the natural emergence and flow of processes; attempting to harness the underlying complexities instead is desirable (Brown \& Eisenhardt, 1997; Garud, Tuertscher, \& Van de Ven, 2013). As highlighted above, in the staged lifecycle model of a support system, the nonlinear interactions that characterize opportunities' emergence are abstracted away for the sake of analytical tractability, despite nonlinear interactions being key to the emergence of patterns (in our case, opportunities). Our paper thus aims to theorize the organizing of early-phase support systems that enable prospective entrepreneurs to interact toward the emergence of entrepreneurial opportunities.

\section{TOWARD NON-LINEAR AND NON-PREDICTIVE VIEW OF EARLY-PHASE SUPPORT SYSTEMS}

We conceptualize the early-phase support system as complex and adaptive, given: (1) the heterogeneity among actors, (2) actors' interrelationships and interactions, (3) openness to its environment, and (4) its capacity to learn, change, and adapt from experience. Complex adaptive systems comprise many interacting parts that evolve and adapt over time (Holland, 1992). Because the cause-effect relationships are nonlinear and the actions of some parts affect those of others, the overall system shows emergent properties that cannot be understood by referring to individual behaviors (Cilliers, 2002; Holland, 1992; Kauffman, 1996; Waldrop, 1992). 
When applying the complex adaptive systems view to organizing (Axelrod \& Cohen, 1999; Lewin, 1999; Miller \& Page, 2007; Stacey, 2007), it is crucial to consider four interrelated elements (Anderson, 1999): first, the presence of actors with a cognitive structure in a system, who, given their perception of the environment, could be purposive and responsive, rather than constrained by fixed rules. Second, maintaining a self-organized state that requires importing energy and information into the system (Prigogine \& Stengers, 1984; Stacey, 2007: 194). Third, as the actors coevolve together, the system moves toward the 'edge of chaos' i.e. it acquires the "ability to bring order and chaos into a special kind of balance" (Eisenhardt \& Brown, 1998; Waldrop, 1992: 12). Finally, as a complex adaptive system, it will evolve through the entry, exit, and transformation of actors (Anderson, 1999: 225). We now discuss how these elements, when taken together, inform our conceptualization of the early-phase support system.

In our conceptualization of the early-phase support system, there are two main sets of actors. The first are "prospective entrepreneurs," who enter the support system to access its resources and engage in interactions with others, hoping for a role in the opportunities and ventures emerging within. The second are "moderators," who intervene and facilitate interactions within the support system. The actors' cognitive structure determines what actions they take as they follow their own implicit rules, informed by their experience, emotions, and beliefs. However, being adaptive actors, these initial rules transform in interactions via feedback, as the actors learn and improve themselves based on what other actors are doing (Hazy \& Uhl-Bien, 2015; Stacey, 2007: 152; Waldrop, 1992: 147). As the actors coevolve, experience strengthens their useful behavioral rules, weakens unhelpful ones, and causes new rules to emerge from combinations and recombination of old ones (Holland, 1992; Waldrop, 1992: 193). Accordingly, the support system moves toward the edge of chaos. The equilibrium that results from such coevolution is dynamic: always unfolding, and in transition (Waldrop, 
1992: 147). Such a process helps the support system to maintain a self-organized state, because it maintains enough balance for "its components [to] never quite lock into place, and yet never quite dissolve into turbulence" (Prigogine \& Stengers, 1984; Stacey, 2007: 194; Waldrop, 1992: 12).

As shown in Figure 1, the ideas of prospective entrepreneurs metaphorically bounce: when they intersect, they create a synergetic outcome; even when they do not intersect, they create a lasting effect on some, while not changing others. These initially unforeseen interactions tend to shift the nonlinear into patterns creating emergent substructures within the support system (Lewin, 1999: 215). Substructures are, therefore, transient patterns that take shape within the space of the support system, self-organizing en route to forming venture concepts (and eventually new ventures). As they form in interactions, these substructures give rise to the emergent property of a venture concept as a holistic token, frame, and premise for further action. Figure 1 shows the substructure of individuals A, B, and E, forming the venture concept "ABE" as the interaction transforms actors and their ideas. Together, the evolving inner substructures and the outer support system form an emergent whole where they mutually influence each other, and one's existence might be indispensable to the other (Walloth, 2016: $22-25)$.

\section{Spatial Dimensions of the Support System}

Central to complex systems is the concept of space, within which relationships emerge (Nonaka et al., 2006) and opportunities form as actors act and interact (Axelrod \& Cohen, 1999: 73). Space is casually interpreted as a dimension "inside which things happen" (Hernes, 2004a: 64), formed through a "boundary-setting...distinction-drawing operation" (Hernes, Bakken, \& Olsen, 2006: 45; Luhmann, 1995). Organizational space could be analyzed along its different types, i.e. physical, social, and mental (Hernes, 2004a); or different conceptions, i.e. as distance, the materialization of power, and experience (Taylor \& Spicer, 2007). Taken 
together, they explain access, control, inclusion, exclusion, and acceptability, within tangible and intangible boundaries (Hernes, 2004b, 2004a; Taylor \& Spicer, 2007; Weinfurtner \& Seidl, 2019). Moreover, as much as space affects how interactions occur, interactions also inform how spaces are configured (Hernes, 2004a; Kornberger \& Clegg, 2004). This recursive relationship between actions and space helps us explain (later in the paper) how substructures emerge within the support system.

Physical space refers to "tangible structures created principally...to regulate work and interaction" (Hernes, 2004a: 71). Within a support system, space can be designed - in terms of proximity and accessibility - to facilitate spontaneous interactions between two prospective entrepreneurs with different expertise and interests. In our example, the startup event could be equally accessible to the chef unfamiliar with the university and the scientist working there. Social space involves trust, identity, and behavioral norms (Hernes, 2004a: 71-72), and is "relations-based," as a "network of relations...[it] regulates much of what is going on" (Hernes, 2004a: 71). Within support systems, social space gives signals about hierarchy, status, and appropriate behavior that members come to adopt (Hernes, 2004a; Taylor \& Spicer, 2007). Mental space is the "space of thought," including "knowledge, learning, and sensemaking" (Hernes, 2004a: 72). Actors might differ in how they make sense of space. In our example, the organized space in the university startup event is experienced differently by the scientist, the forester, and the chef. ${ }^{2}$

\footnotetext{
${ }^{2}$ Digital and virtual tools form the bases for most interactions in today's businesses, and we argue that the support system is no exception. With our formulation of physical space as a material, the materiality can be text, numbers, personas, or schemas on a screen. For this study's purposes, we acknowledge that digital tools are embedded in the physical spaces discussed herein. Digital tools' impact on the (blurring of) boundaries of the space is uncontested. For example, boundaries are made up of electronic means that regulate access to certain electronic domains. However, how the digital tools specifically affect the actions and interactions of actors toward the emergence of venture concepts is beyond this paper's scope. With the advent of COVID19, we are witnessing the virtual replacing the physical. An example of digital support systems being the 'Hack the Crisis' initiatives taking place globally and the thousands of venture concepts that emerged from them. With the 'forced' digitalization and
} 
The configuration of space within the support system brings its boundaries to the forefront for boundaries make different spaces distinct (Weinfurtner \& Seidl, 2019: 14). Boundaries "demarcate distinct organizational spaces and can thus determine the inclusion or exclusion of actions and influence organizations and organizing" (Weinfurtner \& Seidl, 2019: 4). The early and later phase support systems can be explained as two distinct spaces, for example. It is within such space that interactions occur through collaboration and converging interests between various actors (Coenen, Benneworth, \& Truffer, 2012; Hernes, 2004a). In our setting of support systems, when the boundary is permeable, it allows a continuous flow of energy and a critical mass to develop toward self-organizing (Anderson, 1999: 223; Smith \& Comer, 1994; Stacey, 2003). Whether permeable or otherwise, boundaries define the space that actors create, recreate, and reside in (Hernes, 2004b) and express what is 'needed' to get into the space. The support system's boundaries are, therefore, related to the space that is defended, promoted, and integrated (Hernes, 2004a) as they are constructed and reconstructed.

\section{Interventions in the Support System}

The support system is not stand-alone; its functioning requires some form of intervention to influence behavior. Intervention should reflect the characteristics of the targeted phenomenon (Lewin, 1999), namely the emergent and uncertain nature of new venture creation. We conceptualize 'moderators' as the actors who intervene by facilitating interactions in the bottom-up emergence of opportunities within the support system. Importantly, the moderators neither control top-down nor create a priori conditions for emergence. In our case, moderators can neither predict the consequences of their actions (Axelrod \& Cohen, 1999: 13) nor control the direction or envision the specifics or outcome of emergence (Anderson, 1999; Drazin \& Sandelands, 1992). However, their role is not inert (Hazy \& Backström, 2013; Plowman et al., 
2007): their raison d'être is to facilitate, so they constrain the support system by, for example, setting simple rules that might lead to emergent behavior (Cilliers, 2002: 97; Waldrop, 1992: 266). Without moderators, the support system would be too chaotic, producing so much activity that nothing is stable, and structures would collapse almost immediately after forming (Waldrop, 1992: 226). ${ }^{3}$

Actors initially follow their own interaction rules; as a result, their diverse interaction patterns could make the system too chaotic and liable to be overwhelmed by change (Burnes, 2005). Intervention should prevent interactions based solely on the actors' own rules; at the same time, it should also allow for the chance and randomness in entrepreneurial interactions that those rules could generate (Bouchikhi, 1993; Peterson \& Meckler, 2001). The individual entrepreneur's behavioral characteristics are significant, because resource allocation is driven by the "dynamic, institutionally embedded interaction between entrepreneurial attitudes, ability, and aspirations" (Ács, Autio, \& Szerb, 2014: 479). Furthermore, it is also crucial to facilitate the right context, such as acceptance of failure and risk-taking and creating and maintaining an atmosphere of trust and proximity, that encourages sharing scarce resources. Thus, there should be openness to bottom-up processes, acceptance of effective equifinal outcomes, and moderation of dysfunctional tension.

Being adaptive actors, the moderators learn, change, and store this knowledge. With the support system being a non-deterministic system, rules change as people learn (Stacey, 2007: 222), preventing it from settling down to best practices. This is of consequence because, given the heterogeneity of prospective entrepreneurs and their ideas, and the non-linear interactions that take place, the patterns of opportunity they create might differ each time, making the

\footnotetext{
${ }^{3}$ Without moderators, the support system we conceptualize would be akin to an academic conference with no tracks or rules, and open to everyone. This might attract plenty of heterogeneous actors, but their interactions are unlikely to lead to something useful emerging. Although chaos is necessary, it is unproductive without moderators (see, for example, Cilliers, 2002: 97). We thank an anonymous reviewer for highlighting this point.
} 
moderators' role dynamic. The substructures and the venture concepts emerge from lowerlevel interactions that moderators intervene to facilitate (Axelrod \& Cohen, 1999; Gupta, Tesluk, \& Taylor, 2007; Hazy \& Uhl-Bien, 2015; Kogut, 2000). For moderators, the pursuit of a support system existing at the edge of chaos means utilizing simple emergent adaptive rules and learning-centered evolution (Waldrop, 1992: 184), rather than fixed rules, allowing for interesting interactions to take place. Therefore, it is not the outcome but, instead, the propensity or potential for desirable interactions that are facilitated. Under such circumstances, spatial arrangements could induce interactions between individuals who, under normal circumstances, would not have interacted; this can be as simple as placing a coffee machine at a specific corner to create the potential for spontaneous interactions (Fayard \& Weeks, 2007; Gaim, Wåhlin, \& Jacobsson, 2019; Kornberger \& Clegg, 2004). Although interactions and their outcomes cannot be predicted, the potential for them can, thus, be created by design. In combination, these factors either enable or constrain human interaction, thus influencing the emergence of venture concepts.

\section{ORGANIZING EARLY-PHASE SUPPORT SYSTEMS}

In this section, we discuss our model of organizing support systems that enable the emergence of venture concepts en route to realized entrepreneurial opportunities, as depicted in Figure 3.

\section{Insert Figure 3 about here}

Before discussing our model, we first outline the assumption that underlie our core arguments. Actors in the entrepreneurial process display "an openness, orientation, and drive toward seeking out new situations and possibilities and trying new things" (Mitchell, Smith, Seawright, \& Morse, 2000: 978) and in doing so, are willingly susceptible to social influence 
and persuasion (Augier \& Sarasvathy, 2004; Secchi, 2009; Simon, 1959, 1993). In this regard, they place trust on the other and thereby make themselves vulnerable to the actions of another (Korsgaard, Brower, \& Lester, 2015; Mayer, Davis, \& Schoorman, 1995). While engaging in an uncertain and boundedly rational process such as early-phase new-venture creation, this behavior brings "a possible fitness advantage to be realized in social organizations and societies that transmit useful instructions to individuals" (Knudsen, 2003: 240). In general, therefore, we assume that there will be an inclination among prospective entrepreneurs to be trustful of others and engage in interactions with them. However, how this initial trusting behavior further develops depends on the dynamic nature of trust and how it is shaped by the interventions and interactions within the support system.

Given the uncertain and temporary nature of the entrepreneurial process in the early phases, our assumption rests on the notion that without trust, there will not be a support system or any form of organizing. In a context where different parties have to fulfill their role (albeit unspecified) for a relationship to work, trust plays a significant role. Given the context where the outcome is not predetermined, using a contract to safeguard those involved from opportunism (Lui \& Ngo, 2004) would be near impossible. For instance, the benefits from a "good" idea shared and developed within the support system could ultimately be disproportionately appropriated by someone else. Conversely, there might be costs for not entering, or even exiting prematurely, given the high search costs outside (Dew, 2009; Fiet, 1996) and the missed possibility to be part of an emerging opportunity (Sarasvathy \& Dew, 2005; Sarasvathy \& Venkataraman, 2011). Not participating for fear of opportunism would be similar to not entering a tournament for the risk of losing, which does not characterize life both personal and organizational.

The nature of opportunism faced within the support system could be real or perceived. Opportunism, in the real sense, is related to free-riders: the takers who "try to get other people 
to serve their ends while carefully guarding their own expertise and time" (Grant, 2013: 90). However, any rent to be opportunistically realized from the emergence of venture concepts might be non-existent initially as the 'cake is not yet baked,' reducing the chance for opportunism. Moreover, in the early phase, initial disparate ideas have less chance of being stolen because ideas are cheap, and it is the stock of means to realize their potential that is the valuable asset (Sarasvathy, 2001; Wiltbank, Dew, Read, \& Sarasvathy, 2006).

As interactions within the support system progress, being a learning and adapting system, it will eventually drive out free-riders as those who feel taken advantage of might seek to exit the relationships over time (Korsgaard et al., 2015). The interactions within the support system will create enough memory of their opportunistic behavior (Cilliers, 2002: 95), preventing them from further engagement. Moreover, besides cooperation, there will be competition among prospective entrepreneurs to participate in what they consider the best ideas and behaviors: because they are limited, the bad ones would be selected out based on expressed behavior (Levinthal \& Marino, 2015). Thus, a cooperative and mutually trusting (Korsgaard et al., 2015) environment emerges over time, where the behavioral repertoires of prospective entrepreneurs "are biased toward cooperation, rather than opportunism" (Hill, 1990: 511). Despite this, however, the perception that opportunism exists is inherent in uncertain earlyphase relationships. The moderators could intervene to reduce the perception of opportunism by creating a trustful environment that would reassure the prospective entrepreneurs. We elaborate on these interventions in the later sections. We now discuss the core of our model in relation to organizing support systems, along with our propositions.

\section{Openness and Self-Selection}

Openness relates to the nature of the boundaries demarcating an organization's social structure (Kogut, 2000). The degree of openness implies an organization's membership in terms of inclusion and exclusion (Dutton, Dukerich, \& Harquail, 1994; Santos \& Eisenhardt, 
2005). Although organizations are generally variety-reducing entities (Kogut, 2000), their boundaries are open to the extent needed to generate heterogeneity for divergent perspectives and ideas. In general, heterogeneity refers to the differences between individuals in terms of their knowledge, prior experience, behavior, traits, and preferences. Openness allows for not just heterogeneity, but also the similarities sought by prospective entrepreneurs engaging in new-venture creation (Lazar et al., 2020).

In the support system, openness refers to the conditions enabling the inclusion of heterogeneous prospective entrepreneurs within its boundaries. The meeting of these heterogeneous actors' divergent ideas, perceptions, skills, knowledge, experience, and abilities is desirable, because the synthesis of what emerges from these interactions is typically superior to individually held ideas. Moreover, the heterogeneity generated by open boundaries of the support system reduces the search, communication, and coordination costs of the social interactions. As a complex adaptive system, setting the boundaries to allow the flow of resources - in the form of people and their ideas - promotes a conducive environment for spontaneous self-organization into complex structures such as teams, which concomitantly evokes the emergence of venture concepts. Too much openness, however, will result in unmanageable heterogeneity, with highly random interactions and chaos ensuing (Carroll \& Burton, 2000). Moreover, as resources such as moderators and space would be limited, unmanageable openness would reduce the support system's effectiveness. Given these limitations, the moderators could use simple rules that facilitate openness, but restrict its degree of freedom (Cilliers, 2002: 97; Waldrop, 1992: 266) using spatial configurations.

Heterogeneity is also reflected in the varying intentions of prospective entrepreneurs: systematic exploration, spontaneous recognition, and pre-discovery (Dew, 2009). Systematic exploration happens when a potential entrepreneur actively searches for an invention, or an inventor actively seeks innovation possibilities. In spontaneous recognition, an individual 
might encounter a scientific invention that they recognize as a potential innovation. Prediscovery is when contingency and search overlap without prior knowledge. An individual might be unaware of the potential commercialization of their invention, and so store it for potential future use (Garud \& Nayyar, 1994) or never ultimately commercialize it. In the context of openness creating the potential for interactions between these heterogeneous prospective entrepreneurs, it is necessary to identify ways in which they can be brought together to interact within the support system.

Following the complexity sciences literature, we argue that a sufficiently open support system allows the entry, exit, and transformation of prospective entrepreneurs, with the resulting dynamism leading to evolving patterns of interconnections and, therefore, a sense of emergent order (Anderson, 1999; Carlile, 2004; Chiles, Meyer, \& Hench, 2004; Plowman et al., 2007). Prospective entrepreneurs self-select into support systems, driven by their knowledge, aspirations, or serendipitous circumstances. They do so with nothing more than the resources they control, often in the form of prior knowledge or networks (Dimov, 2007; Read, Sarasvathy, Dew, \& Wiltbank, 2016). An actor's self-selection is motivated by the chance to shape emerging opportunities or allow their ideas to be shaped into opportunities by other selfselected actors. As Rogers, Medina, Rivera, \& Wiley (2005: 5) articulate, they gravitate "to the basin-like water flowing to a valley." The support system could channel this similized flow and prevent it from being a trickle or a deluge, as both impede new-venture creation.

The notions of self-selection and inclusion bring us to the boundaries defining the space the actors come into, create, inhabit, and recreate. Permeable boundaries allow a continual flow of energy into a system, as illustrated by the later entry of the industrial designer in Figure 1. Although the moderators cannot fully control the support system boundaries to define the heterogeneity within, because they do not know what the right composition should be, moderators could still rely on multiple mechanisms to facilitate the desired openness. They can 
regulate the space's degree of permeability to set thresholds for entry, which could be malleable in order to allow people and their ideas to move in and out (Hernes, 2004a) easily.

Interventions to manipulate boundaries can take different shapes and forms. For instance, the moderators could announce a simple 'rule' that "on Monday, we discuss food entrepreneurship; all interested are welcome." This rule would allow enough heterogeneity to attract the chef, a food scientist, and a forester, as well as actors from other industries who might want to contribute (such as an industrial designer) while filtering out those who are not sufficiently interested in the topic. With open physical boundaries, prospective entrepreneurs get the possibility of seeing the available resources within and the potential of what could be achieved by taking part. This is analogous to signaling the availability of an "oven" and a "variety of ingredients" for baking, but not predetermining who will bake, what they will bake, or how.

The social boundaries can also be manipulated to signal that diversity is welcome, or to showcase the social assimilation of newcomers, thereby inducing other newcomers to join. Similarly, mental boundaries can be manipulated to import people by availing and making accessible ideas (visions or beliefs) that others might share, such as green technology or data protection and online privacy. If a topic is too esoteric for someone outside the space (or substructure) to participate in the discussion, the boundaries appear impenetrable, thus dissuading them from seeking to move into the space. Esoteric topics can be translated into more accessible terms to enable the majority within the support system to understand them. From these arguments, we derive the following proposition:

Proposition 1a: Modifying the support system's openness by manipulating its boundaries facilitates the self-selection of heterogeneous prospective entrepreneurs.

As prospective entrepreneurs self-select into the support system and form substructures (e.g., "ABE" in Figure 1), boundaries emerge and reproduce through lower-level interactions 
(Giddens, 1979; Hernes, 2004a). At the substructure level, openness refers to the boundaries being permeable for interactions between substructures within the support system (see Figure 4). Within a given space, actors create their own space, as illustrated by the substructure created by $\mathrm{A}, \mathrm{B}$, and $\mathrm{E}$ at $\mathrm{t} 4$ in Figure 1. These emerging substructures exhibit similar characteristics to their overarching support system, with similar complexity and adaptability, but at a lower level (Zimmerman \& Hurst, 1993). Within the support system, moderators could facilitate a general atmosphere of openness with permeability across levels for self-selected actors. To achieve this, the moderators could intervene to place the substructures in a state of flux before they stabilize temporarily or permanently. Interaction across boundaries can be created by design and is manifest in the physical space (e.g., open workspace), mental space (e.g., promoting generosity of sharing ideas and beliefs), and social space (e.g., culture, informal interactions), which are often tied together. For instance, open space symbolizes munificence (Taylor \& Spicer, 2007), and might lead to more interactions, whereas a closed space symbolizes privacy and control (Hatch, 1990), and is less likely to facilitate spontaneous interactions.

Openness makes the substructures dynamic: initially fuzzy, shifting, continually recombining, and changing shape, until a semblance of stability is reached through learning and adaptation. At the beginning of their formation, the substructures are evolving and in a constant state of flux, as heterogeneous prospective entrepreneurs with varying emotions, beliefs, interests, and preferences interact. Based on these heterogeneous factors, they may decide to stay or leave a substructure and explore options in other emerging substructures as they engage in interactions. At this stage, it is less costly to leave than to stay in a nascent substructure because a prospective entrepreneur would not have invested much time and energy, and staying in a substructure with less potential for contributing and gaining is futile. Also, at this stage, the openness of substructures is important, because it allows actor 
interactions and movement across boundaries. Without openness and cross-boundary interactions, the only option would be to stay in a subpar environment or leave the support system entirely. The substructures' fluidity enables prospective entrepreneurs to learn and select a substructure where their contribution would be more valuable.

The spatial configuration of the support system can be designed to encourage members to move and spontaneously interact while maintaining a sense of order. As prospective entrepreneurs in the complex, adaptive support system change to their advantage, they coevolve to the edge of chaos. Thus, with openness, naturally occurring self-organization results from nonlinear interactions, which themselves occur as substructures import energy in from other substructures and the surrounding space ${ }^{4}$ (as shown in Figure 4). This leads to the following proposition:

Proposition 1b: Modifying the substructures' openness by manipulating their boundaries facilitates the self-selection of heterogeneous prospective entrepreneurs.

Insert Figure 4 about here

\section{Visibility and Connectivity}

Openness creates the potential for bringing together actors with varying intentions and means of contributing. However, for this potential to be realized, they should interact with each other, which the intervention should aim to bring about. Providing exact and filtered matches would be a unidimensional and deterministic approach, overlooking that opportunities emerge

\footnotetext{
${ }^{4}$ As shown in Figure 4, some substructures may have impermeable boundaries where actors are unable or unwilling to interact with others. As such, there are high thresholds, which means such substructures strictly regulate what crosses their boundary (Hernes, 2004b).
} 
during serendipitous moments and deliberate searches (Murphy, 2011; Shane, 2008: 69-70). Enough information about active searching could exist only in the form of systematic exploration (see Dew, 2009), because actors with such intentions could have predefined notions about what they are seeking. Nevertheless, moderators might not have the required knowledge to evaluate search needs, leaving limited available options to bring them together. In the complex and uncertain situation that characterizes early-phase support systems, moderators could facilitate nonlinear interactions by helping actors to reveal their entrepreneurial intentions. The visibility created through the revelation of entrepreneurial intentions would induce interested prospective entrepreneurs to converge and interact.

The open and free sharing of ideas will not be practical if the necessary conditions, such as a trustful environment that helps reduce the perception of opportunism, do not exist (Abrams, Cross, Lesser, \& Levin, 2003). In general, people are willing to place their trust in an institutional environment, even without prior experience of dealing with the participants (Mcknight \& Chervany, 1998; Welter, 2012). Given its bidirectional nature (Korsgaard et al., 2015), trust "is neither chosen nor embedded, but is instead learned and reinforced as a product of ongoing interaction and discussion" (Powell, 1996: 63). However, in uncertain environments with few antecedents, this adaptive generation of trust takes place only in an atmosphere of early and swift collective trustworthiness (Kramer, 1999).

An atmosphere of trust is necessitated because moderators need to intervene in ways that accentuate the quality of interaction, rather than merely increasing interaction frequency. To facilitate an atmosphere of early trust within the support system, the moderators could use multiple mechanisms. Trust as behavior could flow across levels: organization-level trust could be internalized and cascade down to create trust between individuals (Kramer, 1999; Miller \& Smith, 1993). Thereby, openness at the support-system level could induce trust, as the system's trust in prospective entrepreneurs could lead them to trust other actors. Initial trust can also be 
generated by having, for instance, a common name tag that identifies each individual entering the support system as an "entrepreneur." Being an entrepreneur, as a shared social identity, could increase trust among the individuals by fostering a collective identity (Korsgaard et al., 2015). Previous participants - preferably successful - could also be asked to convey to newcomers how they benefited from a trustful environment that enabled the open sharing of ideas. Thus, establishing swift early trust could help moderators facilitate each prospective entrepreneur to reveal their ideas and intentions.

Keeping the level of visibility in mind, the moderators could take advantage of the early collective trust by using simple rules like "post your interests, skills, strengths, and competencies on the common board" or by asking prospective entrepreneurs to introduce themselves, their intention and skills on the podium, thus ensuring visibility across the support system. The visibility so created could spur interactions: for instance, although a chef with minimal social ties entering the support system could be initially overwhelmed by its diversity, the heightened visibility of a food scientist seeking to commercialize new food preservation technologies could elicit the chef's engagement. In the atmosphere of trust established, prospective entrepreneurs share, thereby collectively and synergistically creating a generative space that fosters otherwise unavailable options.

Proposition 2a: Self-selected prospective entrepreneurs are more likely to reveal their entrepreneurial intentions as moderators foster an atmosphere of early trust, spurring interactions at the support system-level.

Visibility of intentions could occur first at the level of the support system, and then at the level of its substructures. Consideration of both levels is important because of the risks involved in sharing and revealing one's intentions. Sharing early-phase ideas and intentions need not necessarily be risky for prospective entrepreneurs; on the contrary, it could lead to individual intentions becoming commonly shared goals, as ideas develop. Paradoxically, 
sharing an idea can also protect it by establishing attribution. However, there is a cost associated with sharing vital information at the support-system level; potential entrepreneurs should probably avoid this until they have established some sense of trust within the substructure..$^{5}$

The early collective trust that is created within the support system would set the stage for interactions within the substructures. For the support system to function, the transfer of trust across all levels is paramount. There is, however, a risk that trust might not naturally cascade: this is where the role of the moderator comes in handy to save the system from falling apart. In this regard, Korsgaard et al. (2015) describe trust as a state that is influenced by context and interactions. Social space, as a network of relations, is where norms of behavior regulate much of what occurs (Hernes, 2004a: 71). Trust among actors within substructures, given its bidirectional nature (Korsgaard et al., 2015), will be either enhanced or reduced as an outcome of interactions (Mayer et al., 1995; Powell, 1996: 63). As early trust is established, people will share ideas, although they may refrain from sharing their best ideas. However, with time and as interactions continue and further trust is established in terms of the others' perceived knowledge, ability (competence trust), and integrity (goodwill trust) (Das \& Teng, 2004), they would consider sharing better ideas as interactions strengthen. A dynamics emerge where interactions strengthen early trust, which in turn furthers interactions. However, this doesn't mean that all interactions within the substructures should converge. If the necessary trust is not generated, because of, for example, skepticism, perception of incompetence, or lack of enthusiasm, actors could exit the substructures or the support system altogether. In the process, the substructures could dissolve and feed into others, enabling further interactions within the support system.

\footnotetext{
${ }^{5}$ For actors possessing potentially patentable ideas, the cost might even be higher before the patent is granted. In such cases, they might be better off in a relatively closed setting that differs from what we propose herein.
} 
In principle, asymmetries of trust in relationships exist and need both time (Korsgaard et al., 2015) and interventions to converge. At the substructure level, relationship-based trust among actors could be further strengthened through belonging mechanisms (Hazy \& Uhl-Bien, 2015), including activities that generate specific collective identity (Sheppard \& Tuchinsky, 1996) and reciprocity (Hernes, 2004a: 119; Kreiner \& Schultz, 1993). Interventions in such cases might include physically isolating substructures, thus increasing their potential for interaction within; encouraging them to identify synergies and to establish a collective mission; facilitating feedback sessions; and encouraging substructures to celebrate milestones. Thus, collective identity and reciprocity could be central to long-term trust, which could potentially reduce the risk of opportunism. Within the substructures, as members spend more time together, the sense of shared identity is reflected, for instance, through a team name and logo which would lead to the emergence of a semblance of stability. A sense of belonging and collective mission takes root for the prospective entrepreneurs within, driving them to share their best ideas, enabling further interactions around them.

Proposition 2b: Self-selected prospective entrepreneurs are more likely to reveal their entrepreneurial intentions as moderators help strengthen early trust, spurring further interactions at the substructure-level.

Drawing from connectionism (see Waldrop, 1993: 291), we argue that surprising and sophisticated outcomes occur from the way that prospective entrepreneurs interact within the support system. In our context, we define connectivity within the support system as the quality of interactions between prospective entrepreneurs. We use the quality of interaction to separate connectivity from the amount of interaction: more interaction does not necessarily mean that the interactions are of high quality that could lead to meaningful outcomes. Within the support system, prospective entrepreneurs interact spontaneously and purposively, although the details of that purpose or where that interaction might lead to (e.g., "ABE" in Figure 1) are not defined 
or cannot be articulated in detail. Thus, the intervention could aim to increase connectivity, although the specific outcome of actors as a collective is not predefined but emergent. Connectivity, therefore, entails transforming, rather than adding, to produce something new and different (Born, Frankel, \& Thygesen, 2006: 134). The question that arises is how that "transforming" occurs. We argue that the moderators could intervene in two related ways: lowering associative barriers and moderating power asymmetry.

First, lowering associative barriers occurs when the interacting actors break boundaries (Benedek, Könen, \& Neubauer, 2012). Thus, association across ideas, problems, disciplines, events, and trends is central to connectivity and, ultimately, to the emergence of entrepreneurial opportunities. As people connect concepts that initially appear unconnected, it produces outcomes that were hitherto unpredictable, and likely to be innovative (Dyer, Gregersen, \& Christensen, 2008; Sternberg \& Davidson, 1995). Sailer (2011: 8) argues that "the potential to meet and interact with people holding differing sets of knowledge or beliefs has been argued to be an essentially spatial problem." Therefore, intervention could aim to reduce associative barriers between actors (Johansson, 2004) by designing a space with a suitable spatial configuration in terms of openness, proximity, and density.

Studies show that high visibility triggers more cross-functional interactions (Coradi, Heinzen, \& Boutellier, 2015). As such, open space could increase the visibility of prospective entrepreneurs and their intentions, creating the potential for spontaneous interactions across boundaries. This could generate interactions across substructure boundaries, and is highly likely to enhance their creative potential. Hence, with the potential for equal opportunity for the contribution of heterogeneous actors, lowering associative barriers brings a higher likelihood of emergent entrepreneurial opportunities through the fusion of divergent thinking. Relatedly, by creating a space where failure and the related learning from it is celebrated, a moderator can create a psychologically safe (Edmondson, 1999) environment with "freedom 
to err" (Gaim, 2018: 512), arguably lowering associative barriers and facilitating trial and error, reciprocity, generation of multiple models, and subsequent iterations, such that actors start looking for points of intersection without having to define an anticipated outcome. Associating seemingly unrelated questions, problems, or ideas from different fields, becomes central to the emergence of venture concepts.

Second, because power asymmetry is bound to arise amidst heterogeneity, moderation places actors in the same ground. Moderating power does not mean avoiding conflict, because constructive conflict is essential for creativity and generating new ideas. However, it is undesirable for individual actors to try to gain influence at other actors' expense, thus leading to group disruptions (Amason, 1996) and destructive conflict, especially with power asymmetries between interacting actors (Eisenhardt \& Bourgeois, 1988). Through spatial configuration and moderators' intervention, a prospective entrepreneur who feels overwhelmed in the others' presence could be induced, by exposure to different social stimuli, to engage in spontaneous interaction and rapid transfer of ideas. When those who would have abstained are stimulated to interact, the intervention is said to increase both the quantity and quality of ideas within the collective.

Consider a hypothetical encounter within the support system, that occurs between a multinational company's representative seeking new technologies that could disrupt their industry, and a first-time technology entrepreneur. Their power dynamic might be asymmetrical, rendering the entrepreneur powerless and, hence, hindering interaction. In practice, intervening to moderate such power asymmetry could involve practices akin to "management by wandering around" in the sense that the mere presence of the moderators, whose main task is to facilitate interaction, could change the power dynamics of those engaged in interaction. By just being 'there,' the moderators could engage in ongoing interactions, albeit as neutral observers, to ensure that power relations do not hamper actors' organic interaction. 
Thus, we argue that the moderators could use their presence (in the sense of facilitating instead of monitoring) to change the power dynamics where there is power asymmetry and create a safe space for all involved. Moderation, therefore, aims at creating an atmosphere where connectivity around already visible entrepreneurial intentions of equally valued actors could lead to emergent new opportunities.

Taken together, by moderating associative barriers and power asymmetry within an emerging heterogeneous substructure, the support system could enable prospective entrepreneurs to take the road less traveled. This entails forging a new path outside their specialized areas of expertise and focusing on areas that intersect specialized fields. Hence:

Proposition 3: Higher visibility of the prospective entrepreneurs' intentions could lead to increased connectivity as moderators a) reduce associative barriers and b) manage power asymmetry.

Connectivity represents the quality of interactions: therefore, the higher the connectivity, the better, because, without connectivity, "nothing can proceed from something else" (Hernes, 2007: 78). However, this does not mean that all (or more) interactions are fruitful and of high quality. Not all interactions necessarily establish connectivity. The key message is that the nature and quality of such interactions lead to emergent outcomes. As the connectivity increases within the support system, the substructures begin to take shape, the boundaries of which shield actors from the conventional ways of thinking and doing. This emergent space "allows them to act and interact in ways in which they would not be able to interact outside that isolated space" (Weinfurtner \& Seidl, 2019: 14), and which then goes on to affect how the interactions occur further. As the connectivity increases, the emerging team 'evaluates' the opportunity in time and space, and therefore, their boundaries relatively solidify, and permeability decreases. In this case, an open space's advantage of divergence hampers the 
process as teams reach a stage where there is a need for convergence, which demands a relatively closed space.

At the same time, the overall openness at the support system-level has to be maintained for the potential for interactions to remain (e.g., the industrial designer could come in later as such a potential exists; see Figure 1). The openness that characterizes the support system allows substructures to disband or for particular actors to leave, thereby maintaining interactions across substructures. The emergence of the substructures could be facilitated by allowing for temporary islands of closed spaces, within the overall open space that the support system promotes, where the emerging venture concepts could incubate. Therefore, the support system could have different kinds of spaces within: [1] open spaces where people can freely move around, where the proximity of the various clumps of interactions are within reach and visible, and [2] closed working spaces where some interactions purposely move to secluded areas and away from the chaos as they reach some level of stability.

As the substructures become less open, the prospective entrepreneurs could make use of systematic exploration, wherein they seek new possibilities for emerging opportunities. However, it should also be open enough for others to recognize or discover the potential for engaging with the emerging opportunity. The visibility of the emerging opportunity could be selectively revealed for other actors within the support system. To do so, moderators could modify the spatial dimensions of the substructure by making them designated hotspots, thereby manipulating their boundaries. For instance, if the emerging opportunity is related to food technologies and is designated as such, it would attract the industrial designer or a multinational company's representative who takes an interest in designing food products, and not random interactions from other actors. In interaction with the moderators, the emerging team could evaluate progress and allow for targeted interaction with other actors (such as the industrial designer) whereby the opportunities could evolve. Given the iterative nature of the process, 
once a substructure becomes relatively stabilized by establishing higher connectivity, the openness of the boundaries declines. The increased connectivity reduces the degree of openness as the focus is on targeted interaction based on a best-fit. As substructures emerge, dissipate, and cross feed, multiple stable substructures emerge within the support system that concurrently give rise to multiple venture concepts.

Proposition 4: Increasing connectivity bounds the emerging entrepreneurial opportunities, decreasing the substructures' degree of openness.

Our central argument, therefore, is that the dynamic interplay between openness and connectivity increases the likelihood of venture concepts emerging. Such venture concepts that so emerge might be pursued later by all or some prospective entrepreneurs within a substructure. Albeit at the early phase, the venture concepts have observable manifestations, such as a concept note or a prototype; moreover, these extend beyond the individually held ideas or interactions that have occurred. After transitioning from scattered ideas to venture concepts, the next step is to interact with the external environment and adapt, transform, or perish. The venture concept's fitness or realizability (see Figure 2) will depend on its niche, what other opportunities exist, and what resources it can gather: this is the territory for latephase support systems such as incubators and accelerators.

\section{DISCUSSION}

Our paper inquired how support systems can be organized to enable the actions and interactions of prospective entrepreneurs toward the emergence of venture concepts, as tokens, frames, and premises for further action. In answering our research question, we demonstrated how the interplay between the organizing characteristics of openness, self-selection, visibility, and connectivity creates the potential for venture concepts to emerge (see Figure 3). By exploring the organizing of support systems, we make significant contributions to theory and practice. 


\section{Implications for Research}

We contribute to organizing support systems that are more attuned to the nature of new venture creation that they support. Entrepreneurship scholars have emphasized the pervasive uncertainty and nonlinearity in the early phases of new-venture creation, where opportunities emerge in interactions (Alvarez \& Barney, 2005; Alvarez et al., 2013; Dimov, 2011; Edelman \& Yli-Renko, 2010; Sarasvathy, 2001; Selden \& Fletcher, 2015). However, support systems literature has failed to incorporate these crucial characteristics, and instead predominantly focused on organizing based on a linear and predictable future (Bruneel et al., 2012; Clarysse, Wright, Lockett, Van de Velde, \& Vohora, 2005; Clayton et al., 2018; Mian, Lamine, \& Fayolle, 2016; Rubin et al., 2015).

Therefore, we argue that the paradoxical nature of 'organizing for the emergence of opportunities' has not been adequately integrated into support systems literature. Consequently, the literature does not explain the early phase of opportunity emergence, characterized by uncertainty (with viability yet to be determined) and complexity (given the range of actors with outcomes contingent on who engages in the process, and their possible interactions). In this regard, we extend the literature, which has so far concentrated on organizing support systems for transitioning opportunities from venture concepts to their realization (Autio \& Levie, 2017; Clayton et al., 2018; Cohen et al., 2019; Dutt et al., 2016), by including the phase in which venture concepts emerge from scattered ideas (see Figures 1 and 2). Our findings bridge the gap between the support systems literature and the entrepreneurial opportunities literature, with implications for organizing support systems more attuned to the distinct characteristics of the new venturing phase they aim to support. 
First, support systems literature has predominantly focused on exogenous top-down selection mechanisms at various stages of the support process in determining 'who' or 'what' progresses in the new venture creation process (Aaboen, 2009; Aerts et al., 2007; Clayton et al., 2018). In contrast, we describe the organizational processes by which nonlinear outcomes emerge as heterogeneous actors navigate the various levels of the early-phase support systems' spatial boundaries (Hernes, 2004b, 2004a; Taylor \& Spicer, 2007; Weinfurtner \& Seidl, 2019). These nonlinear outcomes could substitute for (or at least complement) exogenous selection mechanisms, resembling endogenous evolutionary selection (Read et al., 2016). Given that entrepreneurial opportunities form endogenously (Alvarez \& Barney, 2007; Alvarez et al., 2013), wherein prospective entrepreneurs self-select into the new-venture creation process (Lazar et al., 2020; Read et al., 2016); we, therefore, suggest a new direction to support systems literature that explores the facilitation of this process.

Second, whereas most research concerns teams and ideas based on homophily (Aldrich \& Kim, 2007), aspects such as heterogeneity, trust creation, power moderation, and selfdisclosure, need to be considered in the shift toward concurrent self-selection of actors and their self-organization in the early phase of venturing. Because support systems are the result of human choice and intervention, there are decisions that go into affecting how they are organized. Existing research on organizational emergence has either ignored interventions of actors in facilitating emergence (Child \& Rodrigues, 2011; Poulis \& Poulis, 2016) or considered those who intervene as standing apart from the complexity involved and thereby having a unidirectional influence over compliant others (Tourish, 2019). In contrast, by elaborating on the role of moderators - as learning and adaptive actors - we show how they intervene in the nonpredictive emergence of opportunities within support systems, thereby conceptualizing how interventions could play out within the realm of complex organizing (Byrne, 2013; Regine \& Lewin, 2000). Those facilitating do not need to stand apart from the 
processes they try to facilitate, an insight the current support systems literature, with its predominantly linear view of organizing, could benefit from.

Further, our theorizing has broader implications for the literature on organizing earlyphase development processes. It speaks to a wide range of organizational settings such as strategy-making, creativity, corporate entrepreneurship, and innovation, where managerial gatekeepers engage in the selection of ideas in the evolutionary process between idea generation and its eventual outcome (Adner \& Levinthal, 2008; Benner \& Tushman, 2003; Berg, 2016; Burgelman, 1991; Shankar \& Shepherd, 2019). Our research highlights increasing accessibility, heterogeneity, and non-linear interactions as a means to creating requisite variety (Ashby, 1956; Van de Ven, 1986) and facilitating endogenous evolutionary selection in uncertain and resource-constrained environments. We argue that such an understanding could inform early-phase development processes by embracing, rather than reducing, the complexity and uncertainty that characterize their organizing.

Our contributions set the stage for empirical developments in exploring design features of organizing to elucidate the micro-foundations of support systems, focusing predominantly on the uncertain early phases. Specifically, future research could investigate how the design features in different support system contexts (e.g., startup cafes, innovation boot camps, corporate-startup initiatives, hackathons, and new venture creation courses) emerge, develop, and sustain. Our contribution could also spur research on late-phase support systems to reexamine and tightly integrate opportunity emergence in their organizing. Future research could refine our model by manipulating its design features (in terms of boundaries, distance, and movement, for example) and the moderators' simple rules, and improving its applicability in broader settings, perhaps using experimental studies. We also envisage future research to study empirically what actions of moderators will facilitate desirable openness and 
connectivity as they learn from and adapt to the diverse actors and their interactions in different organizational settings.

\section{Implications for Practice}

The example of the StartUp HERE Toronto Café shows that informal chats and unplanned interactions in different settings can open doors, spark ideas, and establish critical new relationships that shape the emergence and development of entrepreneurs' ventures. Our model proposes specific organizing principles for the design of such early phase systems as feeders into the later-stage incubation and acceleration processes. Expedient interventions can keep such systems relevant and attuned to the changing external environment by focusing on bridging scattered ideas and venture concepts (see Figures 1 and 2). In particular, moderators could respond to the demands for openness and closedness of boundaries, both at the support system and team levels. For instance, they could shift the support space from one that facilitates spontaneity and unplanned interactions that could lead to venture concepts and opportunities, to one that facilitates deep work as teams converge around ideas and need to flesh out the venture concepts that need to be incubated.

Our propositions can also inform policymakers who have taken keen interest in support systems as a means of strengthening the entrepreneurial ecosystem within a region (HarperAnderson \& Lewis, 2018). They can complement their emphasis on the late-phase support systems such as incubators and accelerators with enabling early-phase interventions that ensure a stable, vibrant flow of entrepreneurial ideas and initiatives. Given the importance of earlyphase support systems in acting as necessary organizational forms within entrepreneurial ecosystems, our contribution should drive awareness among policymakers of the relevance of investing in them.

\section{CONCLUSION}


The origins and development of new ventures can be traced to many incidents: some designed, others coincidental. Our paper advocates creating the potential for more coincidental actions and interactions, paradoxically within an organized mode, to feed existing support systems. The entrepreneurial ecosystem contains different shapes and forms of support systems, whose presence is integral to effectively organizing various actors with different intentions, resources, and capabilities. Meeting places such as StartUp HERE Toronto Café focus on the early phase of new ventures, increasing the quality and quantity of venture concepts that reach the current support systems. As such, support systems literature could benefit from the increased focus on the early phases in which scattered ideas become venture concepts. Whereas prior research assumes these are generated automatically, and then explains how to develop them into realized opportunities, we elucidate the organizing features behind the emergence of such venture concepts as gateways into the further process. In conjunction with existing support systems research, our study treads a conceptually uninhabited terrain, contributing towards establishing a more holistic view of entrepreneurial ecosystems. 


\section{REFERENCES}

Aaboen, L. 2009. Explaining incubators using firm analogy. Technovation, 29(10): 657-670.

Abrams, L. C., Cross, R., Lesser, E., \& Levin, D. Z. 2003. Nurturing interpersonal trust in knowledge-sharing networks. Academy of Management Perspectives, 17(4): 64-77.

Ács, Z. J., Autio, E., \& Szerb, L. 2014. National systems of entrepreneurship: Measurement issues and policy implications. Research Policy, 43(3): 476-494.

Adner, R., \& Levinthal, D. A. 2008. Doing versus seeing: Acts of exploitation and perceptions of exploration. Strategic Entrepreneurship Journal, 10(2): 43-52.

Aerts, K., Matthyssens, P., \& Vandenbempt, K. 2007. Critical role and screening practices of European business incubators. Technovation, 27(5): 254-267.

Aldrich, H. E., \& Kim, P. 2007. Small worlds, infinite possibilities? How social networks affect entrepreneurial team formation and search. Strategic Entrepreneurship Journal, 1(1-2): 147-165.

Alvarez, S. A., \& Barney, J. B. 2005. How do entrepreneurs organize firms under conditions of uncertainty? Journal of Management, 31(5): 776-793.

Alvarez, S. A., \& Barney, J. B. 2007. Discovery and creation: Alternative theories of entrepreneurial action. Strategic Entrepreneurship Journal, 1(1-2): 11-26.

Alvarez, S. A., Barney, J. B., \& Anderson, P. 2013. Forming and Exploiting Opportunities: The Implications of Discovery and Creation Processes for Entrepreneurial and Organizational Research. Organization Science, 24(1): 301-317.

Amason, A. C. 1996. Distinguishing the effects of functional and dysfunctional conflict on strategic decision making: Resolving a paradox for top management teams. Academy of Management Journal, 39(1): 123-148.

Amezcua, A. S., Grimes, M. G., Bradley, S. W., \& Wiklund, J. 2013. Organizational sponsorship and founding environments: A contingency view on the survival of business-incubated firms, 1994-2007. Academy of Management Journal, 56(6): 16281654.

Anderson, P. 1999. Perspective: Complexity theory and organization science. Organization Science, 10(3): 216-232.

Anderson, P., Meyer, A., Eisenhardt, K., Carley, K., \& Pettigrew, A. 1999. Introduction to the special issue: Applications of complexity theory to organization science.

Organization Science, 10(3): 232-236.

Ashby, R. W. 1956. Requisite Variety. An Introduction to Cybernetics. Englewood Cliffs, NJ: Prentice Hall.

Augier, M., \& Sarasvathy, S. D. 2004. Integrating evolution, cognition and design: Extending Simonian perspectives to strategic organization. Strategic Organization, 2(2): 169-204.

Autio, E., \& Levie, J. 2017. Management of entrepreneurial ecosystems. In G. Ahmetoglu, T. Chamorro-Premuzic, B. Klinger, \& T. Karcisky (Eds.), The Wiley Handbook of Entrepreneurship: 423-449. Chichester: John Wiley \& Sons.

Autio, E., Nambisan, S., Thomas, L. D. W., \& Wright, M. 2018. Digital affordances, spatial affordances, and the genesis of entrepreneurial ecosystems. Strategic Entrepreneurship Journal, 12(1): 72-95. 
Axelrod, R., \& Cohen, M. D. 1999. Harnessing complexity: organizational implications of a scientific frontier. Cambridge: Basic Books.

Benedek, M., Könen, T., \& Neubauer, A. C. 2012. Associative abilities underlying creativity. Psychology of Aesthetics, Creativity, and the Arts, 6(3): 273-281.

Benner, M. J., \& Tushman, M. L. 2003. Exploitation, exploration, and process management : The productivity dilemma revisited. Academy of Management Review, 28(2): 238-256.

Berg, J. M. 2016. Balancing on the Creative Highwire: Forecasting the Success of Novel Ideas in Organizations. Administrative Science Quarterly, 61(3): 433-468.

Bergek, A., \& Norrman, C. 2008. Incubator best practice: A framework. Technovation, 28(1-2): 20-28.

Berglund, H., Bousfiha, M., \& Mansoori, Y. 2020. Opportunities as Artifacts and Entrepreneurship as Design. Academy of Management Review. https://doi.org/10.5465/amr.2018.0285.

Born, A. W., Frankel, C., \& Thygesen, N. T. 2006. The Hours: A Gaze, a Kiss and the Lapse between them. An Eventalization. Ephemera, 6(2): 121-140.

Bouchikhi, H. 1993. A constructivist framework for understanding entrepreneurship performance. Organization Studies, 14(4): 549-570.

Brown, S. L., \& Eisenhardt, K. M. 1997. The art of continuous change : Linking complexity theory and time-paced evolution in relentlessly shifting organizations. Administrative Science Quarterly, 42(1): 1-34.

Bruneel, J., Ratinho, T., Clarysse, B., \& Groen, A. 2012. The Evolution of Business Incubators: Comparing demand and supply of business incubation services across different incubator generations. Technovation, 32(2): 110-121.

Burgelman, R. A. 1991. Intraorganizational Ecology of Strategy Making and Organizational Adaptation : Theory and Field Research. Organization Science, 2(3): 239-262.

Burnes, B. 2005. Complexity theories and organizational change. International Journal of Management Reviews, 7(2): 73-90.

Byrne, D. 2013. Evaluating complex social interventions in a complex world. Evaluation, 19(3): 217-228.

Cardon, M. S., Zietsma, C., Saparito, P., Matherne, B. P., \& Davis, C. 2005. A tale of passion: New insights into entrepreneurship from a parenthood metaphor. Journal of Business Venturing, 20(1): 23-45.

Carlile, P. R. 2004. Transfering, translating, and transforming: An integrative framework for managing knowledge across boundaries. Organization Science, 15(5): 555-568.

Carroll, T., \& Burton, R. M. 2000. Organizations and complexity: searching for the edge of chaos. Computational \& Mathematical Organization Theory, 6(4): 319-337.

Child, J., \& Rodrigues, S. B. 2011. How Organizations Engage with External Complexity: A Political Action Perspective. Organization Studies, 32(6): 803-824.

Chiles, T. H., Meyer, A. D., \& Hench, T. J. 2004. Organizational emergence: The origin and transformation of Branson, Missouri's musical theaters. Organization Science, 15(5): 499-519. 
Cilliers, P. 2002. Complexity and postmodernism: Understanding complex systems. London: Routledge.

Clarysse, B., Wright, M., Lockett, A., Van de Velde, E., \& Vohora, A. 2005. Spinning out new ventures: a typology of incubation strategies from European research institutions. Journal of Business Venturing, 20(2): 183-216.

Clayton, P., Feldman, M., \& Lowe, N. 2018. Behind the scenes: Intermediary organizations that facilitate science commercialization through entrepreneurship. Academy of Management Perspectives, 32(1): 104-124.

Coenen, L., Benneworth, P., \& Truffer, B. 2012. Toward a spatial perspective on sustainability transitions. Research Policy, 41(6): 968-979.

Cohen, S. L., Bingham, C. B., \& Hallen, B. L. 2019. The role of accelerator designs in mitigating bounded rationality in new ventures. Administrative Science Quarterly, 64(4): 810-854.

Coradi, A., Heinzen, M., \& Boutellier, R. 2015. A longitudinal study of workspace design for knowledge exploration and exploitation in the research and development process. Creativity and Innovation Management, 24(1): 55-71.

Das, T. K., \& Teng, B. S. 2004. The risk-based view of trust: A conceptual framework. Journal of Business and Psychology, 19(1): 85-116.

Dew, N. 2009. Serendipity in entrepreneurship. Organization Studies, 30(7): 735-753.

Dew, N., Read, S., Sarasvathy, S. D., \& Wiltbank, R. 2008. Outlines of a behavioral theory of the entrepreneurial firm. Journal of Economic Behavior and Organization, 66(1): 3759.

Dimov, D. 2007. From opportunity insight to opportunity intention: The importance of person-situation learning match. Entrepreneurship: Theory and Practice, 31(4): 561583.

Dimov, D. 2011. Grappling with the unbearable elusiveness of entrepreneurial opportunities. Entrepreneurship: Theory and Practice, 35(1): 57-81.

Dimov, D. 2016. Toward a design science of entrepreneurship. In J. S. Katz \& A. C. Corbett (Eds.), Models of Start-up Thinking and Action: Theoretical, Empirical and Pedagogical Approaches, vol. 18: 1-31. Bingley: Emerald Group Publishing Limited.

Dimov, D. 2020. Opportunities, language, and time. Academy of Management Perspectives. https://doi.org/https://doi.org/10.5465/amp.2017.0135.

Dougherty, D., \& Dunne, D. D. 2012. Digital science and knowledge boundaries in complex innovation. Organization Science, 23(5): 1467-1484.

Drazin, R., \& Sandelands, L. 1992. Autogenesis: A perspective on the process of organizing. Organization Science, 3(2): 230-249.

Dutt, N., Hawn, O., Vidal, E., Chatterji, A., McGahan, A., et al. 2016. How open system intermediaries address institutional failures: The case of business incubators in emerging-market countries. Academy of Management Journal, 59(3): 818-840.

Dutton, J. E., Dukerich, J. M., \& Harquail, C. V. 1994. Organizational images and member identification. Administrative Science Quarterly, 39(2): 239-263.

Dyer, J. H., Gregersen, H. B., \& Christensen, C. 2008. Entrepreneur behaviors, opportunity recognition, and the origins of innovative ventures. Strategic Entrepreneurship 
Journal, 2(4): 317-338.

Edelman, L., \& Yli-Renko, H. 2010. The impact of environment and entrepreneurial perceptions on venture-creation efforts: Bridging the discovery and creation views of entrepreneurship. Entrepreneurship: Theory and Practice, 34(5): 833-856.

Edmondson, A. 1999. Psychological safety and learning behavior in work teams. Administrative Science Quarterly, 44(2): 350-383.

Eisenhardt, K. M., \& Bourgeois, L. J. 1988. Politics of strategic decision making in highvelocity environments: Toward a midrange theory. Academy of Management Journal, 31(4): 737-770.

Eisenhardt, K. M., \& Brown, S. L. 1998. Competing on the edge: Strategy as structured chaos. Long Range Planning, 31(5): 786-789.

Fayard, A.-L., \& Weeks, J. 2007. Photocopiers and water-coolers: The affordances of informal interaction. Organization Studies, 28(5): 605-634.

Feldman, M., Siegel, D. S., \& Wright, M. 2019. New developments in innovation and entrepreneurial ecosystems. Industrial and Corporate Change, 28(4): 817-826.

Fiet, J. O. 1996. The informational basis of entrepreneurial discovery. Small Business Economics, 8(6): 419-430.

Gaim, M. 2018. On the emergence and management of paradoxical tensions: The case of architectural firms. European Management Journal, 36(4): 497-518.

Gaim, M., Wåhlin, N., \& Jacobsson, M. 2019. The role of space for a paradoxical way of thinking and doing: A study of idea work in architectural firms. Creativity and Innovation Management, 28(2): 265-281.

Garud, R., \& Giuliani, A. P. 2013. A narrative perspective on entrepreneurial opportunities. Academy of Management Review, 38(1): 157-160.

Garud, R., \& Nayyar, P. R. 1994. Transformative capacity: Continual structuring by intertemporal technology transfer. Strategic Management Journal, 15(5): 365-385.

Garud, R., Tuertscher, P., \& Van de Ven, A. H. 2013. Perspectives on innovation processes. The Academy of Management Annals, 7(1): 775-819.

Giddens, A. 1979. Introduction. Central Problems in Social Theory. Berkeley: University of California press.

Grant, A. 2013. In the company of givers and takers. Harvard Business Review, 91(4): 9097.

Gupta, A. K., Tesluk, P. E., \& Taylor, M. S. 2007. Innovation at and across multiple levels of analysis. Organization Science, 18(6): 885-897.

Harper-Anderson, E., \& Lewis, D. A. 2018. What Makes Business Incubation Work? Measuring the Influence of Incubator Quality and Regional Capacity on Incubator Outcomes. Economic Development Quarterly, 32(1): 60-77.

Hatch, M. J. 1990. The symbolics of office design: an empirical exploration. In P. Gagliardi (Ed.), Symbols and artifacts: Views of the corporate landscape: 129-146. New York: Routledge.

Hazy, J. K., \& Backström, T. 2013. Human interaction dynamics (HID): Foundations, definitions, and directions. Emergence: Complexity and Organization, 15(4): 91-111. 
Hazy, J. K., \& Uhl-Bien, M. 2015. Towards operationalizing complexity leadership: How generative, administrative and community-building leadership practices enact organizational outcomes. Leadership, 11(1): 79-104.

Hernes, T. 2004a. The spatial construction of organization, vol. 12. Amsterdam: John Benjamins Publishing.

Hernes, T. 2004b. Studying composite boundaries: A framework of analysis. Human Relations, 57(1): 9-29.

Hernes, T. 2007. Understanding organization as process: Theory for a tangled world. London: Routledge.

Hernes, T., Bakken, T., \& Olsen, P. I. 2006. Space, organizations and management theory. In S. Clegg \& M. Kornberger (Eds.), Advances in Organization Studies, vol. 17: 44. Copenhagen: Copenhagen Business School Press.

Hill, C. W. L. 1990. Cooperation, opportunism, and the invisible hand: Implications for transaction cost theory. Academy of Management Review, 15(3): 500-513.

Holland, J. H. 1992. Complex adaptive systems. Daedalus, 121(1): 17-30.

Johansson, F. 2004. The medici effect. Boston, MA: Harvard Business Review Press.

Kauffman, S. 1996. At home in the universe: The search for the laws of self-organization and complexity. New York: Oxford university press.

Knudsen, T. 2003. Simon's selection theory: Why docility evolves to breed successful altruism. Journal of Economic Psychology, 24(2): 229-244.

Kogut, B. 2000. The network as knowledge: Generative rules and the emergence of structure. Strategic Management Journal, 405-425.

Kornberger, M., \& Clegg, S. R. 2004. Bringing space back in: Organizing the generative building. Organization Studies, 25(7): 1095-1114.

Korsgaard, M. A., Brower, H. H., \& Lester, S. W. 2015. It isn't always mutual: A critical review of dyadic trust. Journal of Management, 41(1): 47-70.

Kramer, R. 1999. Trust and distrust in organizations: Emerging perspectives, enduring questions. Annual Review of Psychology, 50(1): 569-598.

Kreiner, K., \& Schultz, M. 1993. Informal collaboration in R \& D. The formation of networks across organizations. Organization Studies, 14(2): 189-209.

Lazar, M., Miron-Spektor, E., Agarwal, R., Erez, M., Goldfarb, B., et al. 2020. Entrepreneurial Team Formation. Academy of Management Annals, 14(1): 29-59.

Levinthal, D. A., \& Marino, A. 2015. Three facets of organizational adaptation: Selection, variety, and plasticity. Organization Science, 26(3): 743-755.

Lewin, A. Y. 1999. Application of Complexity Theory to Organization Science. Organization Science, 10(3): 215-215.

Lichtenstein, B. B., Dooley, K. J., \& Lumpkin, G. T. 2006. Measuring emergence in the dynamics of new venture creation. Journal of Business Venturing, 21(2): 153-175.

Luhmann, N. 1995. Social systems. Stanford, CA: Stanford University Press.

Lui, S. S., \& Ngo, H. yue. 2004. The role of trust and contractual safeguards on cooperation in non-equity alliances. Journal of Management, 30(4): 471-485. 
Mayer, R. C., Davis, J. H., \& Schoorman, F. D. 1995. An Integrative Model of Organizational Trust. Academy of Management Review, 20(3): 709-734.

McDonald, R., \& Gao, C. 2019. Pivoting isn't enough? Managing strategic reorientation in new ventures. Organization Science, 30(6): 1289-1318.

Mcknight, D. H., \& Chervany, N. L. 1998. Initial trust formation in new organizational relationships. Academy of Management Review, 23(3): 473-490.

Mcmullen, J. S., \& Dimov, D. 2013. Time and the entrepreneurial journey: The problems and promise of studying entrepreneurship as a process. Journal of Management Studies, 50(8): 1481-1512.

Mian, S., Lamine, W., \& Fayolle, A. 2016. Technology business incubation: An overview of the state of knowledge. Technovation, 50-51(2): 1-12.

Mihata, K. 1997. The persistence of 'emergence.' In R. Eve \& L. Mary (Eds.), Chaos, Complexity \& Sociology: Myths, Models \& Theories: 30-38. Sage Publications: Thousand Oaks, CA.

Miller, G. J., \& Smith, R. W. 1993. Managerial dilemmas: The political economy of hierarchy. Cambridge: Cambridge University Press.

Miller, J. H., \& Page, S. E. 2007. Complexity in Social Worlds. Complex adaptive systems: An Introduction to Computational Models of Social Life: 9-31. Princeton, NJ: Princeton university press.

Mitchell, R. K., Smith, J. B., Seawright, K. W., \& Morse, E. A. 2000. Cross-cultural cognitions and the venture creation decision. Academy of Management Journal, 43(5): 974-993.

Murphy, P. J. 2011. A $2 \times 2$ conceptual foundation for entrepreneurial discovery theory. Entrepreneurship: Theory and Practice, 35(2): 359-374.

Nair, S., \& Blomquist, T. 2019. Failure prevention and management in business incubation: practices towards a scalable business model. Technology Analysis and Strategic Management, 31(3): 266-278.

Nair, S., \& Blomquist, T. 2020. The temporal dimensions of business incubation: A valuecreation perspective. International Journal of Entrepreneurship and Innovation, 21(1): 38-46.

Packard, M. D., \& Clark, B. B. 2019. On the mitigability of uncertainty and the choice between predictive and non-predictive strategy. Academy of Management Review, Inpress. https://doi.org/https://doi.org/10.5465/amr.2018.0198.

Pauwels, C., Clarysse, B., Wright, M., \& Van Hove, J. 2016. Understanding a new generation incubation model: The accelerator. Technovation, 50-51: 13-24.

Peterson, M. F., \& Meckler, M. R. 2001. Cuban-American entrepreneurs: Chance, complexity and chaos. Organization Studies, 22(1): 31-57.

Plowman, D. A., Solansky, S., Beck, T. E., Baker, L. K., Kulkarni, M., et al. 2007. The role of leadership in emergent, self-organization. Leadership Quarterly, 18(4): 341-356.

Poulis, K., \& Poulis, E. 2016. Problematizing fit and survival: Transforming the law of requisite variety through complexity misalignment. Academy of Management Review, 41(3): 503-527.

Powell, W. W. 1996. Trust-based forms of governance. In R. M. Kramer \& T. R. Tyler 
(Eds.), Trust in organizations: Frontiers of theory and research: 51. London: Sage.

Prigogine, I., \& Stengers, I. 1984. Order out of chaos: Man's new dialogue with nature. New York: Bantam. New York: Bantam New Age Books.

Read, S., Sarasvathy, S. D., Dew, N., \& Wiltbank, R. 2016. Response to Arend, Sarooghi, and Burkemper (2015): Cocreating effectual entrepreneurship research. Academy of Management Perspectives, 41(3): 528-536.

Regine, B., \& Lewin, R. 2000. Leading at the edge: How leaders influence complex systems. Emergence, 2(2): 5-23.

Rogers, E. M., Medina, U. E., Rivera, M. a, \& Wiley, C. J. 2005. Complex adaptive systems and the diffusion of innovations. The Innovation Journal: The Public Sector Innovation Journal, 10(3): 1-26.

Roundy, P. T., Brockman, B. K., \& Bradshaw, M. 2017. The resilience of entrepreneurial ecosystems. Journal of Business Venturing Insights, 8(11): 99-104.

Rubin, T. H., Aas, T. H., \& Stead, A. 2015. Knowledge flow in technological business incubators: evidence from Australia and Israel. Technovation, 41: 11-24.

Sailer, K. 2011. Creativity as social and spatial process. Facilities, 29(1/2): 6-18.

Santos, F. M., \& Eisenhardt, K. M. 2005. Organizational boundaries and theories of organization. Organization Science, 16(5): 491-508.

Sarasvathy, S. 2001. Causation and effectuation: Toward a theoretical shift from economic inevitability to entrepreneurial contingency. Academy of Management Review, 26(2): 243-263.

Sarasvathy, S. D., \& Dew, N. 2005. Entrepreneurial logics for a technology of foolishness. Scandinavian Journal of Management, 21(4 SPEC. ISS.): 385-406.

Sarasvathy, S. D., \& Venkataraman, S. 2011. Entrepreneurship as method: Open questions for an entrepreneurial future. Entrepreneurship: Theory and Practice, 35(1): 113-135.

Secchi, D. 2009. The cognitive side of social responsibility. Journal of Business Ethics, 88(3): 565-581.

Selden, P. D., \& Fletcher, D. E. 2015. The entrepreneurial journey as an emergent hierarchical system of artifact-creating processes. Journal of Business Venturing, 30(4): 603-615.

Shane, S. A. 2008. The illusions of entrepreneurship: The costly myths that entrepreneurs, investors, and policy makers live by. Yale: Yale University Press.

Shankar, R. K., \& Shepherd, D. A. 2019. Accelerating strategic fit or venture emergence: Different paths adopted by corporate accelerators. Journal of Business Venturing, 34(5): 1-19.

Sheppard, B. H., \& Tuchinsky, M. 1996. Micro-OB and the network organization. In R. M. Kramer \& T. R. Tyler (Eds.), Trust in organizations: Frontiers of theory and research: 140-165. London: Sage.

Simon, H. A. 1959. Theories of decision-making in economics and behavioral science. The American Economic Review, 49(3): 253-283.

Simon, H. A. 1993. Altruism and economics. The American Economic Review, 83(2): 156161. 
Smith, C., \& Comer, D. 1994. Self-organization in small groups: A study of group effectiveness within non-equilibrium conditions. Human Relations, 47(5): 553-581.

Spigel, B. 2017. The relational organization of entrepreneurial ecosystems. Entrepreneurship: Theory and Practice, 41(1): 49-72.

Spigel, B., \& Harrison, R. 2018. Toward a process theory of entrepreneurial ecosystems. Strategic Entrepreneurship Journal, 12(1): 151-168.

Stacey, R. D. 2003. Complexity and group processes: A radically social understanding of individuals. New York: Brunner-Routlege.

Stacey, R. D. 2007. Strategic management and organisational dynamics: The challenge of complexity to ways of thinking about organisations (5th ed.). Harlow: Prentice Hall.

Startup Here Toronto cafe. 2018. Startup here Toronto cafe. https://startupheretoronto.com/startup-here-toronto-cafe/.

Sternberg, R. J., \& Davidson, J. E. 1995. The nature of insight. Cambridge: The MIT Press.

Taylor, S., \& Spicer, A. 2007. Time for space: A narrative review of research on organizational spaces. International Journal of Management Reviews, 9(4): 325-346.

Tourish, D. 2019. Is Complexity Leadership Theory Complex Enough? A critical appraisal, some modifications and suggestions for further research. Organization Studies, 40(2): 219-238.

Townsend, D. M., Hunt, R. A., McMullen, J. S., \& Sarasvathy, S. D. 2018. Uncertainty, knowledge problems, and entrepreneurial action. Academy of Management Annals, 12(2): 659-687.

Van de Ven, A. H. 1986. Central Problems in the Management of Innovation. Management Science, 32(5): 590-607.

van de Ven, A. H., \& Poole, M. S. 1995. Explaining development and change in organizations. Academy of Management Review, 20(3): 510-540.

Vogel, P. 2016. From venture idea to venture opportunity. Entrepreneurship: Theory and Practice, 41(6): 943-972.

Waldrop, M. M. 1992. Complexity: The Emerging Science at the Edge of Order and Chaos, vol. 45. New York: Simon and Schuster.

Walloth, C. 2016. Emergent Nested Systems: A Theory of Understanding and Influencing Complex Systems as Well as Case Studies in Urban Systems. New York: Springer.

Weinfurtner, T., \& Seidl, D. 2019. Towards a spatial perspective: An integrative review of research on organisational space. Scandinavian Journal of Management, 35(2): 1-30.

Welter, F. 2012. All you need is trust? A critical review of the trust and entrepreneurship literature. International Small Business Journal, 30(3): 193-212.

Wiltbank, R., Dew, N., Read, S., \& Sarasvathy, S. D. 2006. What to do next? The case for non-predictive strategy. Strategic Management Journal, 27(10): 981-998.

Zimmerman, B. J., \& Hurst, D. K. 1993. Breaking the boundaries: The fractal organization. Journal of Management Inquiry, 2(4): 334-355. 


\section{FIGURE 1}

From Scattered Ideas to Venture Concepts

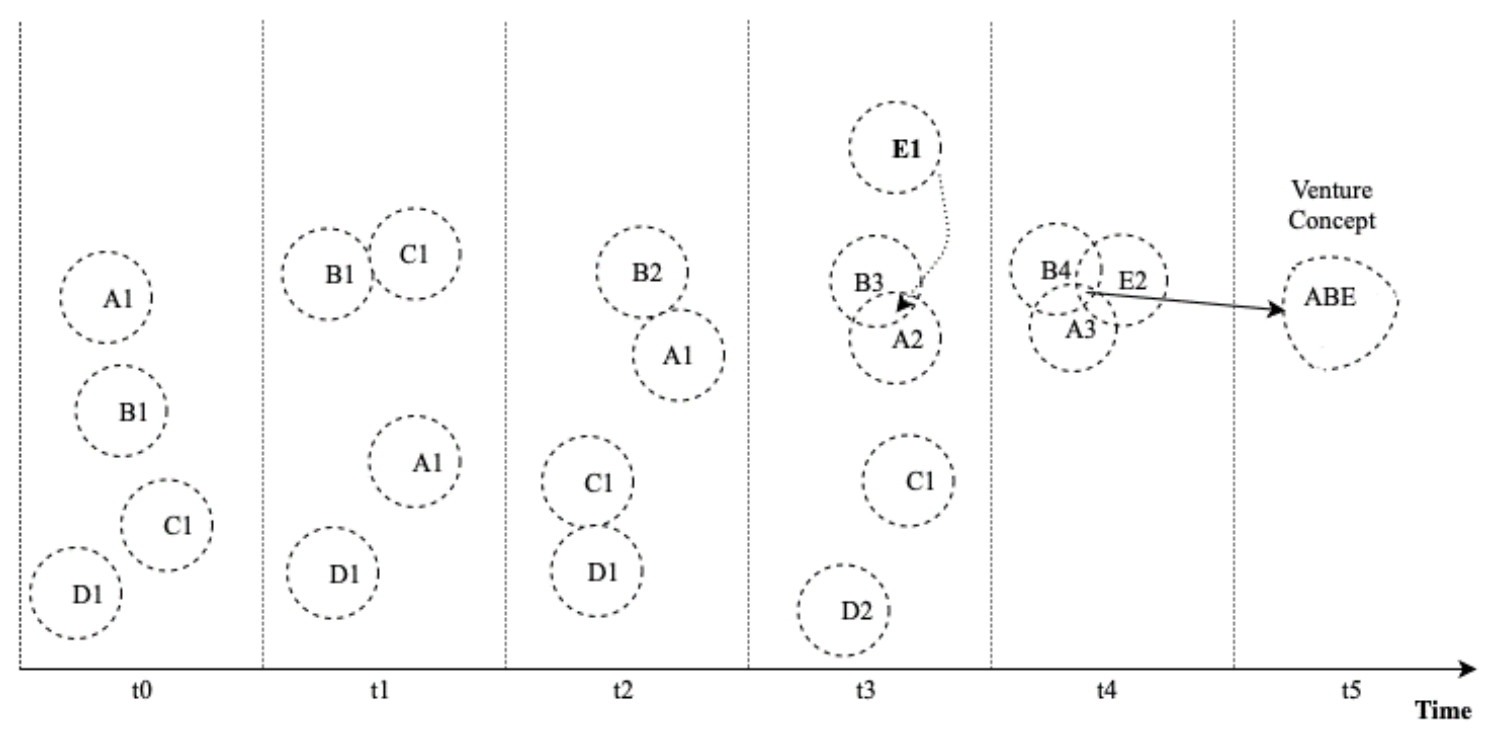

A: Chef B: Food Scientist C: Plant Scientist D: Forester E: Industrial designer

\section{FIGURE 2}

From Scattered Ideas to Venture Concepts and then Realized Opportunities

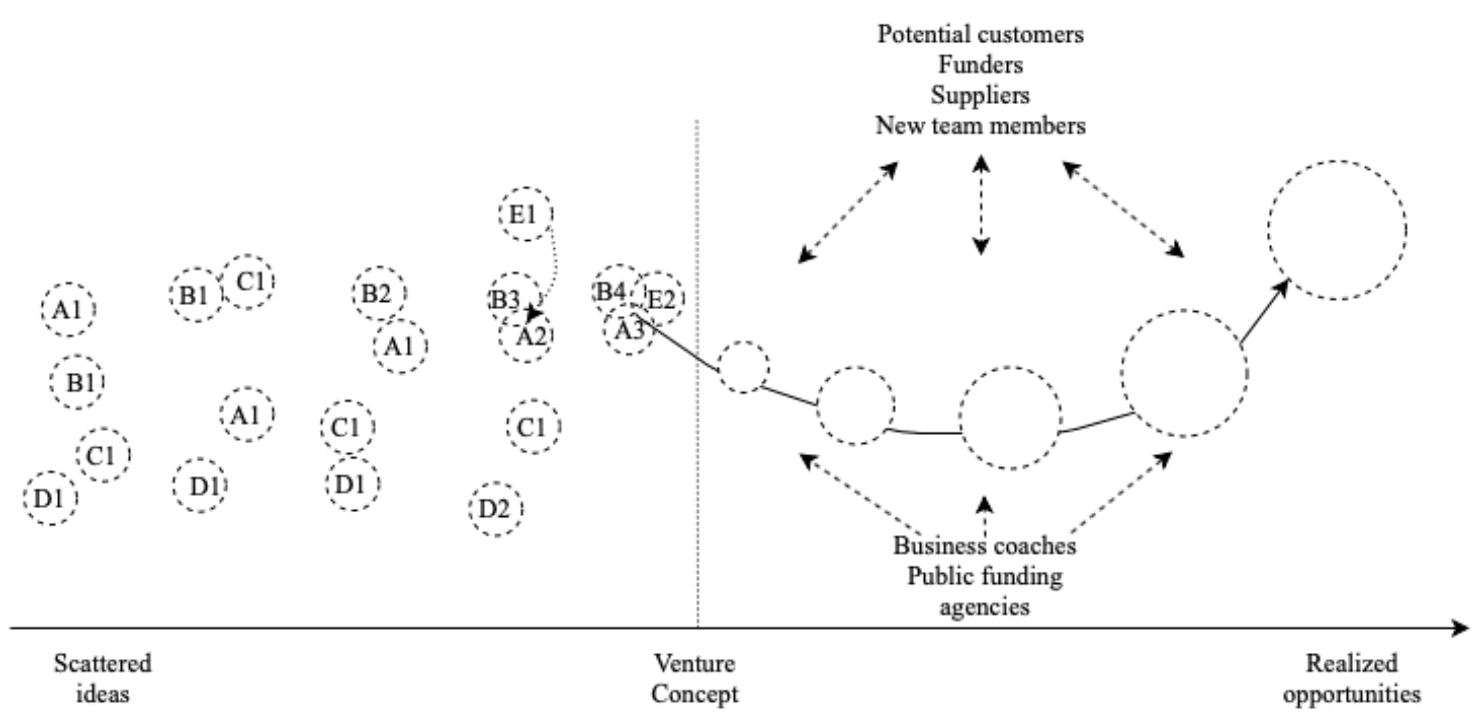


FIGURE 3

A Model of Organizing Support Systems

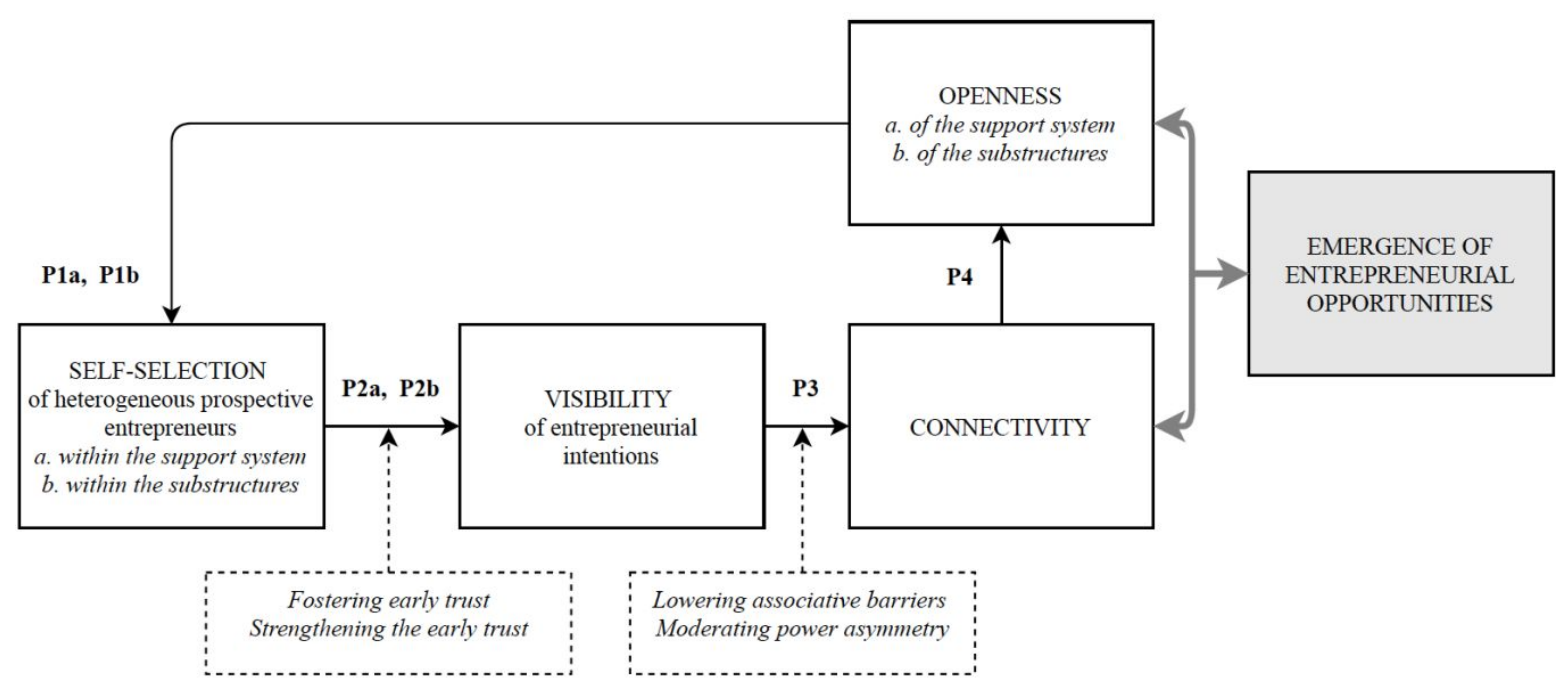

FIGURE 4

The Boundaries and Actors of the Support System

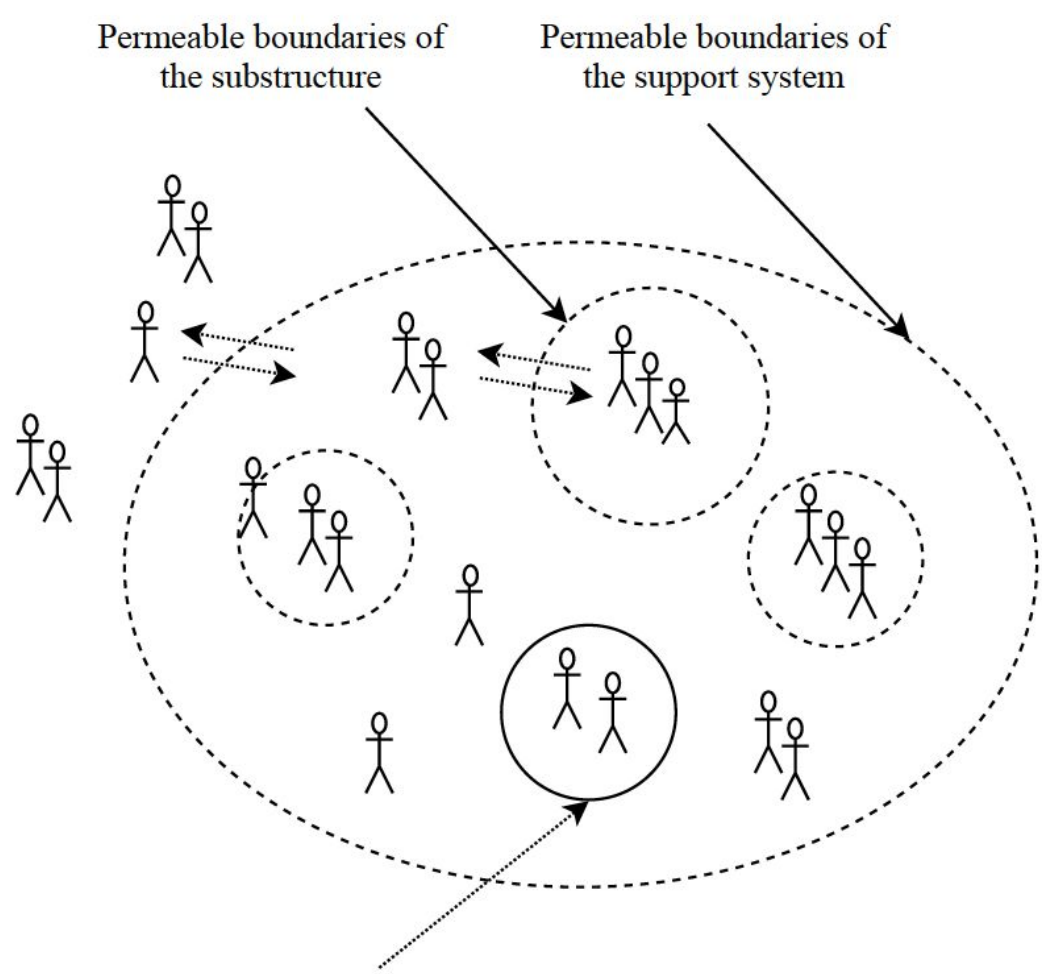

Substructures with impermeable boundaries 


\section{Author Biographical Statements}

Sujith Nair (sujith.nair@umu.se) is Associate Professor of Entrepreneurship at Umeå School of Business, Economics and Statistics, Umeå University, Sweden. His research focuses on new venture creation, entrepreneurial ecosystems and the emergence of technological innovations.

Medhanie Gaim (medhanie.gaim@umu.se) is Assistant Professor of Management at Umeå School of Business, Economics and Statistics, Umeå University, Sweden. His research focuses on on paradox theory, entrepreneurial ecosystems and new venture creation.

Dimo Dimov (d.p.dimov@bath.ac.uk) is Professor of Entrepreneurship and Innovation at University of Bath, UK and visiting professor at Reykjavik University, Iceland. His research focuses on entrepreneurial thinking, processes, and practice. 